\title{
Fluoride Bridges as Structure-Directing Motifs in 3d-4f Cluster Chemistry
}

Birk, Torben; Pedersen, Kasper; Thuesen, Christian Aa.; Weyhermuller, Thomas; Schau-Magnussen, Magnus; Piligkos, Stergios; Weihe, Hogni; Mossin, Susanne; Evangelisti, Marco; Bendix, Jesper

\section{Published in:}

Inorganic Chemistry

Link to article, DOI:

10.1021/ic300421x

Publication date:

2012

Document Version

Publisher's PDF, also known as Version of record

Link back to DTU Orbit

Citation (APA):

Birk, T., Pedersen, K., Thuesen, C. A., Weyhermuller, T., Schau-Magnussen, M., Piligkos, S., Weihe, H., Mossin, S., Evangelisti, M., \& Bendix, J. (2012). Fluoride Bridges as Structure-Directing Motifs in 3d-4f Cluster Chemistry. Inorganic Chemistry, 51(9), 5435-5443. https://doi.org/10.1021/ic300421x

\section{General rights}

Copyright and moral rights for the publications made accessible in the public portal are retained by the authors and/or other copyright owners and it is a condition of accessing publications that users recognise and abide by the legal requirements associated with these rights.

- Users may download and print one copy of any publication from the public portal for the purpose of private study or research.

- You may not further distribute the material or use it for any profit-making activity or commercial gain

- You may freely distribute the URL identifying the publication in the public portal 


\title{
Fluoride Bridges as Structure-Directing Motifs in 3d-4f Cluster Chemistry
}

\author{
Torben Birk, ${ }^{\dagger}$ Kasper S. Pedersen, ${ }^{\dagger}$ Christian Aa. Thuesen, ${ }^{\dagger}$ Thomas Weyhermüller, ${ }^{\ddagger}$ \\ Magnus Schau-Magnussen, ${ }^{\dagger}$ Stergios Piligkos, ${ }^{\dagger}$ Högni Weihe, ${ }^{\dagger}$ Susanne Mossin, ${ }^{\S}$ Marco Evangelisti, ${ }^{\perp}$ \\ and Jesper Bendix* ${ }^{*}$ \\ ${ }^{\dagger}$ Department of Chemistry, University of Copenhagen, Universitetsparken 5, DK-2100 Copenhagen, Denmark \\ ${ }^{\ddagger}$ Max Planck Institute for Bioinorganic Chemistry, D-45470 Mülheim an der Ruhr, Germany \\ ${ }^{\S}$ Department of Chemistry, Technical University of Denmark, DK-2800 Kgs. Lyngby, Denmark \\ ${ }^{\perp}$ Instituto de Ciencia de Materiales de Aragón, Departamento de Física de la Materia Condensada, CSIC-Universidad de Zaragoza, \\ 50009 Zaragoza, Spain
}

\section{Supporting Information}

ABSTRACT: The use of kinetically robust chromium(III) fluorido complexes as synthons for mixed $3 \mathrm{~d}-4 \mathrm{f}$ clusters is reported. The tendency toward linear $\left\{\mathrm{Cr}^{\mathrm{III}}-\mathrm{F}-\mathrm{Ln}^{\mathrm{III}}\right\}$ units dictates the cluster topology. Specifically, we show that reaction of cis- $\left[\mathrm{Cr}^{\mathrm{III}} \mathrm{F}_{2}(\mathrm{NN})_{2}\right] \mathrm{NO}_{3}(\mathrm{NN}=$ 1,10-phenanthroline ("phen") or 2,2'-bipyridine ("bpy")) with Ln$\left(\mathrm{NO}_{3}\right)_{3} \cdot x \mathrm{H}_{2} \mathrm{O}$ produces isostructural series of molecular $\left\{\operatorname{Ln}_{2} \mathrm{Cr}_{2}\right\}$ squares (1-9) with linear fluoride bridges. In a parallel fashion, fac$\left[\mathrm{Cr}^{\mathrm{III}} \mathrm{F}_{3} \mathrm{~L}\right]$, where $\mathrm{L}=N, N^{\prime}, N^{\prime \prime}$-trimethyl-1,4,7-triazacyclononane (" $\mathrm{Me}_{3}$ tacn"), reacts with $\mathrm{Nd}\left(\mathrm{NO}_{3}\right)_{3} \cdot 6 \mathrm{H}_{2} \mathrm{O}$ to form a fluoride-centered penta-nuclear complex and $f a c-\left[\mathrm{Cr}^{\mathrm{III}} \mathrm{F}_{3} \mathrm{~L}^{\prime}\right]$, with $\mathrm{L}^{\prime}=1,1,1$-tris((methylamino)methylethane) (" $\mathrm{Me}_{3}$ tame"), reacts with [Ln(hfac) $\left.{ }_{3}\left(\mathrm{H}_{2} \mathrm{O}\right)_{2}\right]$ (hfacH $=1,1,1,5,5,5$-hexafluoroacetylacetone) to yield an isostructural series of $\left\{\mathrm{Ln}_{3} \mathrm{Cr}_{2}\right\}(10-14)$ trigonal bipyramids with no

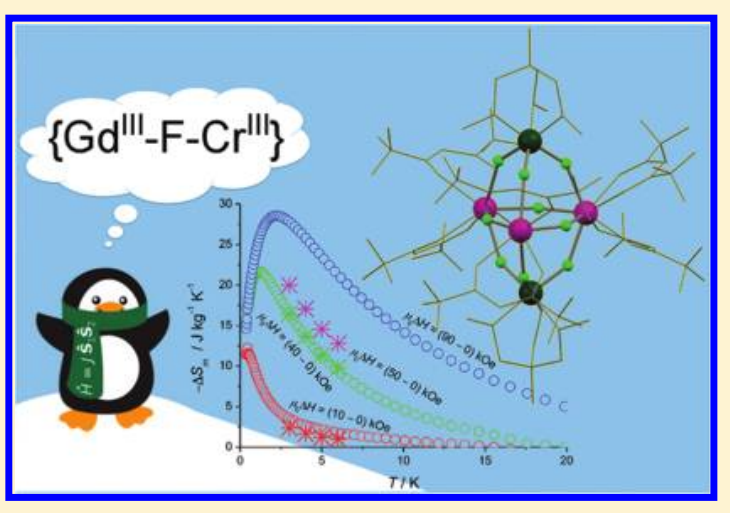
central ligand. The formation of the latter is accompanied by a partial solvolysis of the $\mathrm{Cr}$ (III) precursor but without formation of insoluble $\mathrm{LnF}_{3}$. The magnetic properties of the gadolinium containing clusters allow quantification of fluoride-mediated, antiferromagnetic $\mathrm{Gd}-\mathrm{Cr}$ exchange interactions of magnitude between $0.14 \mathrm{~cm}^{-1}$ and $0.71 \mathrm{~cm}^{-1}\left(\hat{H}=J_{12} \hat{\mathbf{S}}_{1} \cdot \hat{\mathbf{S}}_{2}\right.$ formalism) and vanishingly small $J_{\mathrm{Gd}-\mathrm{Gd}}$ of $0.06(0) \mathrm{cm}^{-1}$. The large spin and small anisotropy together with weak exchange interactions in the $\left\{\mathrm{Gd}_{3} \mathrm{Cr}_{2}\right\}$ (11) cluster give rise to a very large magneto-caloric effect of $-\Delta S_{\mathrm{m}}=28.7 \mathrm{~J} \mathrm{~kg}^{-1} \mathrm{~K}^{-1}\left(\mu_{0} \mathrm{H}=90\right.$ to $\left.0 \mathrm{kOe}\right)$.

\section{INTRODUCTION}

Interest in high-nuclearity clusters incorporating lanthanoid ions has been boosted by the quest for magnetically anisotropic molecular systems as single-molecule magnets, ${ }^{1}$ and, more recently, the increasing focus on nanoscopic coolers ${ }^{2}$ has established a need for molecular entities exhibiting very-large spin ground states. Presently, the vast majority of mixed $3 \mathrm{~d}-4 \mathrm{f}$ clusters are bridged by large organic ligands or smaller entities such as hydroxide or especially alkoxides whereas valenceisoelectronic fluoride bridges are exceedingly scarce. ${ }^{3}$ Reported examples of fluoride-bridging included, until recently, only systems with diamagnetic $\mathrm{Ti}(\mathrm{IV})$ ions, namely, [La$\left.\left\{\left(\mathrm{C}_{5} \mathrm{Me}_{4} \mathrm{Et}\right)_{2} \mathrm{Ti}_{2} \mathrm{~F}_{7}\right\}_{3}\right]^{4}$ and $\left[\mathrm{Ln}\left\{\left(\mathrm{C}_{5} \mathrm{Me}_{5}\right)_{2} \mathrm{Ti}_{2} \mathrm{~F}_{7}\right\}_{3}\right](\mathrm{Ln}=\mathrm{Pr}$, $\mathrm{Nd})^{5}$ in which the 12-coordinate lanthanoid ion is exclusively surrounded by fluoride ions. Recently, ${ }^{6}$ fluoride-bridged systems were augmented by lanthanoid-containing wheels or fused wheels featuring fluoride bridges in conjunction with pivalate bridges between chromium(III) and lanthanoids. As discussed by Winpenny and co-workers, the synthesis of fluoride-bridged $3 \mathrm{~d}-4 \mathrm{f}$ clusters is hampered by the strong affinity of lanthanoid(III) ions for fluoride resulting in competitive formation of highly insoluble $\mathrm{LnF}_{3}$. The abovementioned titanium complexes probably owe their existence to the comparable affinity of "hard" $\mathrm{Ti}(\mathrm{IV})$ and the lanthanide ion for fluoride. Thus, the successful isolation of those polynuclear systems is most likely irrelevant for the majority of other transition metal ions. However, relying on kinetics rather than thermodynamics the use of kinetically robust transition metal (TM) fluoride complexes, for example, of chromium(III), may be a generally feasible approach provided the synthesis can be carried out relatively fast and at moderate temperatures. In the synthesis of mixed $3 \mathrm{~d}-4 \mathrm{f}$ clusters topological control is difficult to achieve because of the flexibility in coordination number and geometry of the lanthanoid ions and frequent solvent coordination. There are

Received: February 24, 2012 
very few accessible mono- or diatomic bridges which have not been extensively explored. Its simplicity, spectroscopic innocence, relatively low basicity, and preference for "hard" metal ions make fluoride an attractive bridging ligand for mixed transition metal-lanthanoid complexes. Furthermore, the tendency toward pseudolinear bridging established in transition metal chemistry could facilitate prediction and design of specific molecular topologies, if it can be shown to carry over into lanthanoid chemistry. To exploit the latter property of the fluoride ligand, it is necessary to target simple systems with unsupported fluoride bridges. This will also allow for a quantification of the magnetic interaction via the fluoride bridge, which was not possible in the wheels wherein the fluoride bridge coexists with one or two pivalate bridges.

Useful building blocks for polynuclear fluoride-bridged $3 \mathrm{~d}-4 \mathrm{f}$ systems would be robust di- or trifluorido complexes of $\mathrm{Cr}$ (III) preferably with polydentate coligands and soluble in organic solvents. Such difluorido precursors are well described in literature with the auxiliary ligand sphere consisting of amines or imines, for example, cis- $\left.\left[\mathrm{CrF}_{2} \text { (phen }\right)_{2}\right] \mathrm{NO}_{3}{ }^{8}$ Additionally, neutral trifluorido analogues can be obtained by minor modifications of published synthetic procedures. 9 'Here we describe the syntheses and properties of a class of simple chromium(III)-lanthanide clusters starting from di- and trifluorido complexes of chromium: cis- $\left[\mathrm{CrF}_{2}(\mathrm{NN})_{2}\right]^{+}(\mathrm{NN}=$ phen, bpy), fac- $\left[\mathrm{CrF}_{3}\left(\mathrm{Me}_{3}\right.\right.$ tame $\left.)\right]$, and $f a c-\left[\mathrm{CrF}_{3}\left(\mathrm{Me}_{3} \mathrm{tacn}\right)\right]$.

\section{RESULTS AND DISCUSSION}

We have recently, demonstrated the formation of bimetallic fluoride bridged linear rods or squares obtained by using robust trans- $\left[\mathrm{CrF}_{2}(\mathrm{py})_{4}\right]^{+}(\mathrm{py}=\text { pyridine })^{10}$ or cis- $\left[\mathrm{CrF}_{2}(\mathrm{phen})_{2}\right]^{+11}$ respectively, as building blocks. This type of reactivity is generalizable, and $1: 1$ assembly reactions in methanolic solution of cis- $\left.\left[\mathrm{CrF}_{2} \text { (phen }\right)_{2}\right] \mathrm{NO}_{3}$ and $\mathrm{Ln}\left(\mathrm{NO}_{3}\right)_{3} \cdot$ aq yield tetranuclear clusters, which crystallize as solvates with the general formula $\left[\left\{\mathrm{CrF}_{2}(\text { phen })_{2}\right\}_{2}\left\{\mathrm{Ln}\left(\mathrm{NO}_{3}\right)_{4}\right\}_{2}\right] \cdot 4 \mathrm{MeOH} \cdot \mathrm{H}_{2} \mathrm{O}$ $(\mathrm{Ln}=\mathrm{Ce}-\mathrm{Nd}, \mathrm{Sm}-\mathrm{Ho}(\mathbf{1}-\mathbf{9}))$. Yields diminish pronouncedly with increasing atomic number of the lanthanide and no product is obtained at all for the heaviest ones $(\mathrm{Er}-\mathrm{Yb})$. The decreasing yield with increasing atomic number is accompanied by an increasing amount of an easily separable byproduct, which is not $\mathrm{LnF}_{3}$, as determined by analysis and powder diffraction. The exact nature of the byproduct has however not been determined. Freshly precipitated, and not too intensely dried, the tetranuclear compounds are isomorphous and crystallize in the tetragonal space group $P 4 / n c c$ as demonstrated by the powder diffraction data for the series Ce-Dy (except $\mathrm{Pm}$ ) in Figure 1. Upon thorough drying the crystal solvents are lost, as witnessed by elemental analyses and deterioration of the crystals.

The cis-coordination of the two fluoride ions imposes a square structure on the resulting tetranuclear cluster with almost linear $\left(169^{\circ}\right) \mathrm{Ln}-\mathrm{F}-\mathrm{Cr}$ bridges (cf. Figure 2). The lanthanide ion is deca-coordinated with four bidentate nitrate ligands and two bridging fluoride ligands. The coordination number is smaller than usual in bidentate nitrate complexes where coordination numbers of 11 and 12 are common, but it is also found in, for example, $\left[\mathrm{Nd}\left(\mathrm{NO}_{3}\right)_{4}\left(\mathrm{CH}_{3} \mathrm{OH}\right)_{2}\right]^{-12}$ The coordination around chromium is very similar to that in the parent complex, but with slightly elongated $\mathrm{Cr}-\mathrm{F}$ bond lengths $1.8816(14) / 1.8844(17) \AA$ as compared to $1.8444(10)-$ $1.8621(10) \AA$ in $\left[\mathrm{CrF}_{2}(\text { phen })_{2}\right]\left(\mathrm{ClO}_{4}\right) \cdot \mathrm{H}_{2} \mathrm{O} .^{13}$

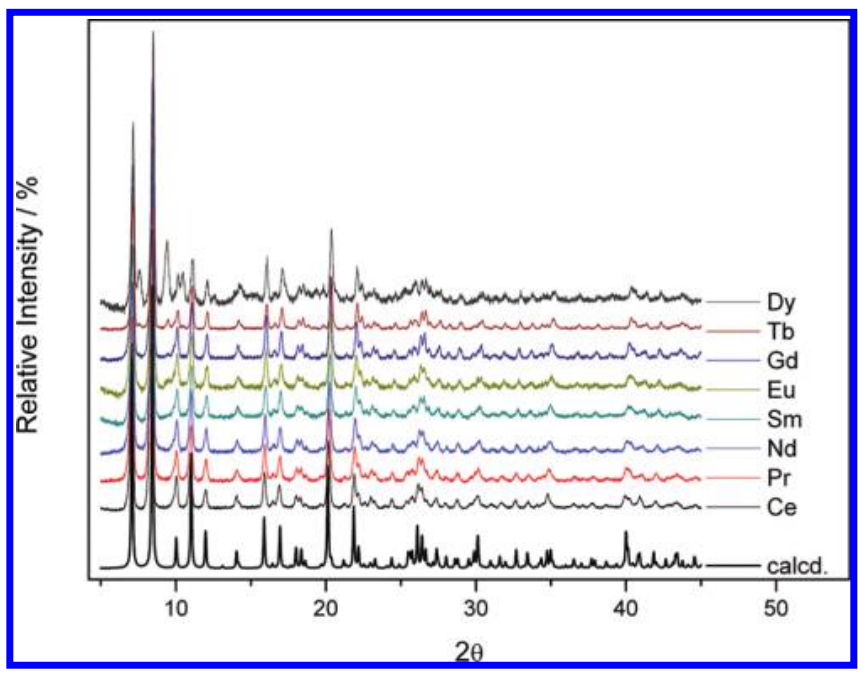

Figure 1. Powder diffraction patterns for $\left[\left\{\mathrm{CrF}_{2}(\mathrm{phen})_{2}\right\}_{2}\{\mathrm{Ln}\right.$ $\left.\left.\left(\mathrm{NO}_{3}\right)_{4}\right\}_{2}\right] \cdot 4 \mathrm{MeOH} \cdot \mathrm{H}_{2} \mathrm{O}(\mathbf{1 - 8})$. The lower trace is calculated on basis of the single crystal diffraction data for the gadolinium compound. The yields diminish steeply with increasing atomic weight of the lanthanoid and amounts to less than $2 \%$ for the Dy-compound (cf. Experimental Section). The low-angle part of the powder diffraction also demonstrates the Dy-compound to contain a crystalline impurity.

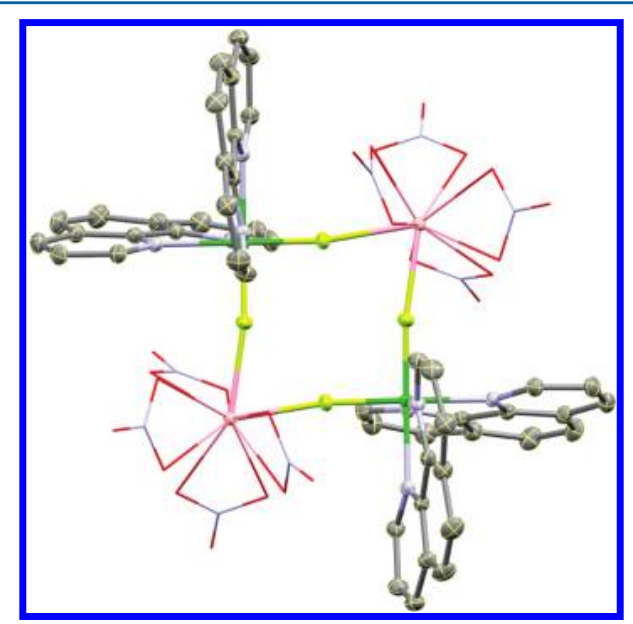

Figure 2. X-ray molecular structure of the isostructural metal clusters in 6 and 3, for comparison shown with thermal ellipsoids (50\% probability). Hydrogens and solvent molecules are omitted and nitrate ligands have been shown as wireframes for clarity. Color code: pink, Ln; green, Cr; yellow, F; red, O; blue, N; gray, C. Selected bond lengths $(\AA)$ and angles (deg), for 6: $\mathrm{Cr}-\mathrm{F}: 1.8844(17) ; \mathrm{Cr}-\mathrm{N}$ : 2.058(2)-2.063(2); Gd-F: 2.2844(16); Gd-O: 2.506(2)-2.533(2); Cr-F-Gd: 168.61(9). For 3: Cr-F: 1.8816(14); Cr-N: 2.0550(17)2.0615(19); Nd-F: 2.3348(15); Nd-O: 2.5326(19)-2.5651(18); Cr-F-Nd: $168.74(8)$.

The $\mathrm{Cr}-\mathrm{N}$ distances are at $2.0550(17)-2.063(2) \AA$ in the same range as found in the monomeric precursor: $2.0566(15)-$ 2.0934(15) A. The crystallographic symmetry, which connects different clusters by 4-fold screw-axes ensures all clusters to be oriented with parallel $\mathrm{Cr}_{2} \mathrm{Ln}_{2}$-planes in the packing (see the Supporting Information).

The closely related cis- $\left[\mathrm{CrF}_{2}(\mathrm{bpy})_{2}\right]^{+}$reacts analogously and furnishes structurally similar fluoride-bridged tetranuclear clusters. However, these systems are void of solvents of crystallization and crystallize with lower symmetry in orthorhombic I222 (cf. Supporting Information). It is note- 
worthy, that the cis configuration of the fluoride ligands in $\left.\left[\mathrm{CrF}_{2} \text { (phen) }\right)_{2}\right]^{+}$does not suffice to introduce chelate binding toward the lanthanoid ions. A similar result has recently been observed for a homometallic tetranuclear manganese(II) cluster: $\left.\left[\mathrm{Mn}_{4}{ }_{4} \mathrm{~F}_{4} \text { (phen }\right)_{8}\right]\left(\mathrm{NO}_{3}\right)_{4} \cdot 12 \mathrm{H}_{2} \mathrm{O}^{14}$ and parallels the tetra-nuclear structures with approximately linear fluoride bridges found for many metal pentafluorides. Thus, while many examples are known with doubly bridging hydroxide, oxide, and the heavier halides, fluoride clearly disfavors this structural motif. This conclusion becomes even more evident when the products resulting from reaction between trifluorido complexes of $\mathrm{Cr}$ (III) and lanthanoid complexes are considered. Scheme 1 depicts the structures obtained with the di- and

Scheme 1. Structure Diagrams of the Polynuclear Complexes Obtained from Di- and Trifluorido Chromium(III) Building Blocks $^{a}$

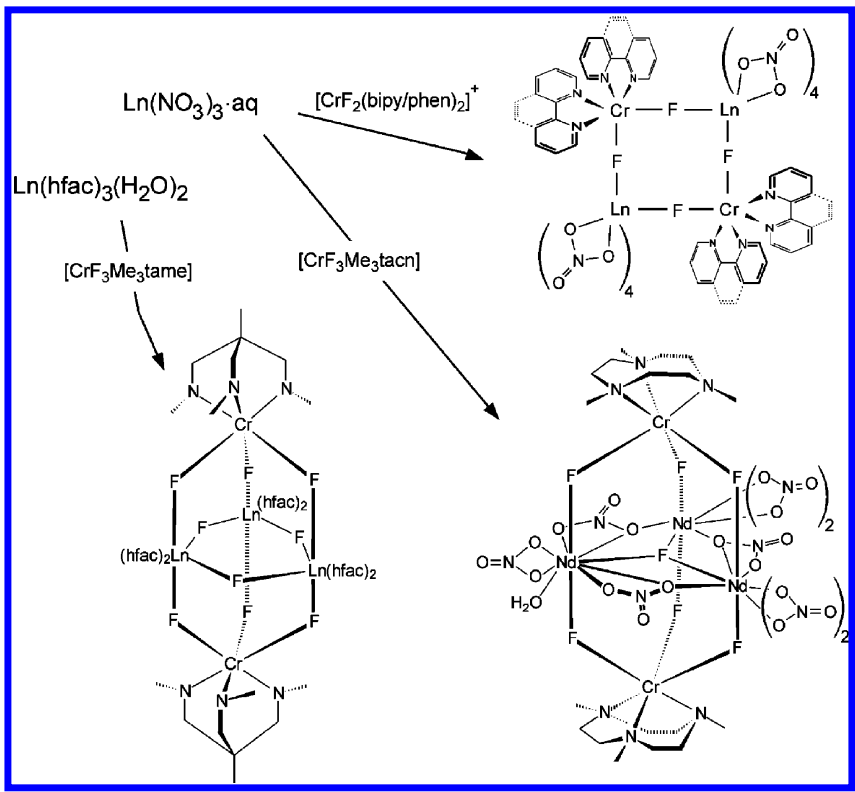

${ }^{a}$ The complete absence of chelating binding towards the lanthanoid centers illustrates the tendency of fluoride bridges to avoid bending.

trifluorido complexes. Thus, for both $\mathrm{fac}-\left[\mathrm{CrF}_{3}\left(\mathrm{Me}_{3} \mathrm{tame}\right)\right]$ and $\mathrm{fac}-\left[\mathrm{CrF}_{3}\left(\mathrm{Me}_{3} \mathrm{tacn}\right)\right]$, pentanuclear structures were obtained from acetonitrile solutions using respectively [Ln$\left.(\mathrm{hfac})_{3}\left(\mathrm{H}_{2} \mathrm{O}\right)_{2}\right](\mathrm{Ln}=\mathrm{Sm}(10), \mathrm{Gd}(11), \mathrm{Ho}$ (12), Yb (13); hfacH $=1,1,1,5,5,5$-hexafluoroacetylacetone) and $\mathrm{Nd}$ $\left(\mathrm{NO}_{3}\right)_{3} \cdot 6 \mathrm{H}_{2} \mathrm{O}$ as lanthanoid sources. Both types of structures consist of triangular arrangements of the lanthanoid ions bridged in the equatorial plane by either bidentate and bridging

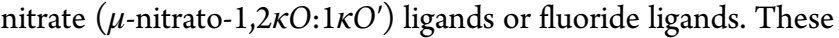
triangles are then capped above and below the plane by tridentate, but nonchelating, $\left\{\mathrm{LCrF}_{3}\right\}$ moieties. Additionally, the system derived from $\mathrm{fac}$ - $\left[\mathrm{CrF}_{3}\left(\mathrm{Me}_{3} \mathrm{tacn}\right)\right]$ features a most unusual central $\mu_{3}$-fluorido ligand bridging all three neodymium centers symmetrically. This bridging mode is very rare, but not completely unprecedented in transition metal chemistry where examples of planar $\mu_{3}-\mathrm{F}$ bridging fluoride exist in, for example, $\left[\mathrm{Ni}_{3}\left(\mu_{3}-\mathrm{F}\right)\left(\mathrm{CF}_{3} \mathrm{CO}_{2}\right)_{6}\left(\mathrm{CF}_{3} \mathrm{CO}_{2} \mathrm{H}\right)_{3}\right]^{-15}$ The overall 3-fold symmetry of the clusters is broken by different equatorial coordination environments of the lanthanoids and associated small variations in $\mathrm{Ln}-\mathrm{F}$ bond lengths toward the $\left\{\mathrm{CrLF}_{3}\right\}$ moieties.
Crystal structures of the pentanuclear systems are shown in Figure 3. An important feature of the structures is the

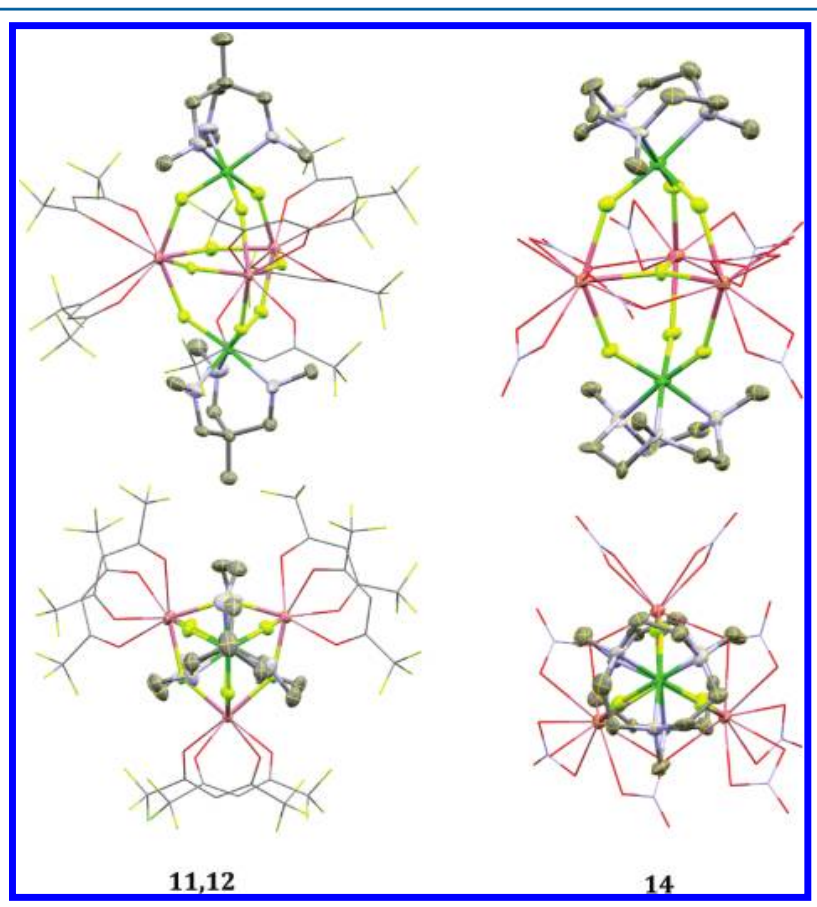

Figure 3. Side and top views of crystal structures of $\left[\left\{\mathrm{CrF}_{3}\left(\mathrm{Me}_{3} \mathrm{tame}\right)\right\}_{2} \mathrm{Ln}_{3}(\mathrm{hfac})_{6}(\mu-\mathrm{F})_{3}\right] \cdot 7 \mathrm{CH}_{3} \mathrm{CN}(\mathrm{Ln}=\mathrm{Gd}(\mathbf{1 1}), \mathrm{Ho}$ (12); left) and $\left[\left\{\mathrm{CrF}_{3}\left(\mathrm{Me}_{3} \mathrm{tacn}\right)\right\}_{2} \mathrm{Nd}_{3}\left(\mathrm{NO}_{3}\right)_{8}\left(\mu_{3}-\mathrm{F}\right)-\right.$ $\left.\left(\mathrm{H}_{2} \mathrm{O}\right)\right] \cdot 6 \mathrm{CH}_{3} \mathrm{CN}$ (14; right). Solvent molecules and hydrogens have been omitted for clarity. Thermal ellipsoids ( $50 \%$ probability) have only been given for the inner cores, peripheral ligands have been shown as wireframes for clarity. Color code: pink, $\mathrm{Ln}$; green, $\mathrm{Cr}$; yellow, F; red, O; blue, N; gray, C. Selected bond lengths $(\AA)$ and angles (deg), 11: Cr1-F: 1.903(7)-1.915(7), Cr2-F: 1.903(6)$1.912(7), \mathrm{Cr} 1-\mathrm{N}: 2.043(12)-2.053(12), \mathrm{Cr} 2-\mathrm{N}: 2.057(11)-$ 2.066(12), Gd-F $\mathrm{F}_{\mu-\mathrm{Cr}}: 2.295(6)-2.338(7), \mathrm{Gd}-\mathrm{F}_{\mu-\mathrm{Gd}}: 2.216(6)-$ 2.244(7), Gd-O: 2.39(3)-2.49(2), Cr-F-Gd: 142.8(3)-146.6(3), Gd-F-Gd: 142.3(3)-143.9(4),12: Cr1-F: 1.893(4)-1.904(4), Cr2-F: 1.892(4)-1.915(4), Cr1-N: 2.055(8)-2.062(7), Cr2-N: $2.044(7)-2.055(7), \mathrm{Ho}-\mathrm{F}_{\mu-\mathrm{Cr}}: 2.256(4)-2.311(4), \mathrm{Ho}-\mathrm{F}_{\mu-\mathrm{Ho}}$ : 2.189(4)-2.200(4), Ho-O: 2.35(3)-2.463(19), Cr-F-Ho: 143.3(2)-145.5(2), Ho-F-Ho: 143.3(2)-146.9(2),14: Cr1-F: 1.894(8)-1.936(8), Cr2-F: 1.918(9)-1.938(8), Cr1-N: 2.040(12)-2.095(12), $\mathrm{Cr} 2-\mathrm{N}: 2.075(12)-2.094(13), \mathrm{Nd} 1-$ $\mathrm{F} 120\left(\mu_{3}\right): 2.365(8), \mathrm{Nd} 2-\mathrm{F} 120\left(\mu_{3}\right): 2.434(8), \mathrm{Nd} 3-\mathrm{F} 120\left(\mu_{3}\right)$ : 2.410(7), Nd1-O: 2.489(11)-2.542(10), Nd2-O: 2.508(11)$2.652(11), \mathrm{Nd} 3-\mathrm{O}: 2.499(10)-2.626(10), \mathrm{Nd} 1-\mathrm{F}_{\mu-\mathrm{Cr}}: 2.297(8)-$ $2.326(8), \quad \mathrm{Nd} 2-\mathrm{F}_{\mu-\mathrm{Cr}}: 2.342(8)-2.353(8), \mathrm{Nd} 3-\mathrm{F}_{\mu-\mathrm{Cr}}: 2.372(8)-$ 2.386(8). Cr-F-Nd: 138.5(4)-146.8(4), Nd-O-Nd: 109.4(4)$110.0(4)$.

additional bridging fluoride ligands $\left(\mu_{3}\right.$ or $\left.\mu_{2}\right)$, which demonstrates that even quite robust $\mathrm{Cr}$ (III) fluoride complexes are susceptible to fluoride abstraction by lanthanoid ions under mild conditions (cf. Experimental Section). However, despite of this, formation of very insoluble $\mathrm{LnF}_{3}$ was never observed under the experimental conditions used to prepare these polynuclear complexes. Although the $\mathrm{Cr}-\mathrm{F}-\mathrm{Ln}$ bridges in 11, 12 , and 14 are significantly bent at angles of $138.6-146.8^{\circ}$, it is striking that the facial trifluorido complexes avoid chelate binding of a single lanthanoid ion despite the lability and size of the lanthanoid ions. This is again paralleled by the transition metal fluoride chemistry where tri- $\mu_{2}$-fluorido complexes are scarce in comparison with the abundance of tri- $\mu_{2}$-hydroxido 
and tri- $\mu_{2}$-chlorido complexes. In combination these observations attest to a pronounced preference for linear bridging by fluoride, which pertains to systems with lanthanoid ions. This geometric preference is reminiscent of the behavior of cyanide as a bridging ligand and it might, therefore, render robust fluoride complexes, appealing building blocks for assembly of polynuclear systems with targeted topologies.

In the structures of 11 and $12, \mathrm{Cr}-\mathrm{F}-\mathrm{Ln}$ and $\mathrm{Ln}-\mathrm{F}-\mathrm{Ln}$ bridging angles are very similar and both close to $140^{\circ}$. However, this similarity should not be overinterpreted since the trigonal bipyramidal structures in combination with the metalfluoride bond lengths restrict the bridging angles, which are thus compromises between linear bridging and optimal bond lengths. Since the preparations invariably involve hydrated starting materials, it could be speculated, that some of the fluorides alternatively could be assigned as isoelectronic hydroxide ligands. The X-ray structures of 11 and 12 were both solved with hydroxide in place of the equatorial fluoride bridges with very little effect on the goodness of the modeling, which only slightly, but not statistically significantly favors fluoride bridges. However, electrospray mass spectrometry (vide infra) only reveals intact clusters and fragments with fluoride bridges and thus rules out the presence of hydroxide bridges.

The polynuclear solid state structures described above are not merely consequences of crystal packing, but reflect association also in solution. When methanolic solutions of cis$\left.\left[\mathrm{CrF}_{2} \text { (phen }\right)_{2}\right] \mathrm{NO}_{3}$ and $\mathrm{Gd}\left(\mathrm{NO}_{3}\right) \cdot \mathrm{aq}$ are mixed to yield solutions with different ratios of $\mathrm{Gd} / \mathrm{Cr}$ (ranging from 0 to $2)$, there is an associated color change from red-purple to orange. The ligand-field (LF) spectrum of $\mathrm{Cr}$ (III) changes, resulting in a blue shift of the first spin-allowed band, ${ }^{4} \mathrm{~T}_{2}(O) \leftarrow{ }^{4} \mathrm{~A}_{2}(O)$, of $460 \mathrm{~cm}^{-1}$ (cf. Figure 4). Since the position

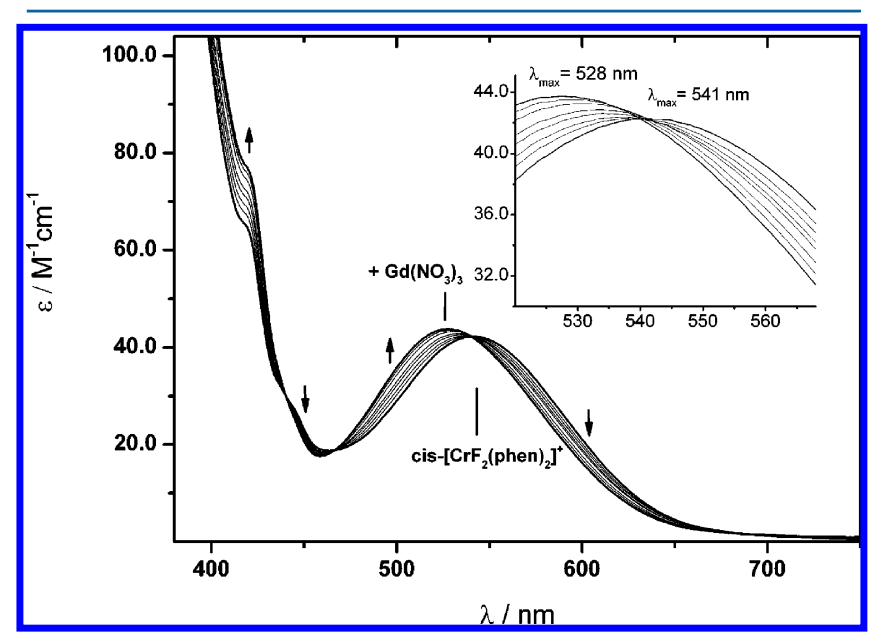

Figure 4. UV-vis spectral changes upon addition of $\mathrm{Gd}\left(\mathrm{NO}_{3}\right)_{3}$ to cis$\left.\left[\mathrm{CrF}_{2} \text { (phen }\right)_{2}\right] \mathrm{NO}_{3}$ in methanol/acetonitrile (1:4). Spectra were recorded over $30 \mathrm{~min}$ at room temperature (RT). Prolonged storage or further addition of $\mathrm{Gd}\left(\mathrm{NO}_{3}\right)_{3}$ results in precipitation of 6 .

of this band directly measures the octahedral component of the ligand-field, the direction of the shift toward higher energies might seem counterintuitive. However, shifts of the same sign and even larger magnitude were found for $f a c-\left[\mathrm{CrF}_{3}\left(\mathrm{Me}_{3} \mathrm{tacn}\right)\right]$ interacting with $\mathrm{Na}^{+}$ions in 2-propanol. ${ }^{9}$ It has also generally been found that $\mathrm{Cr}$ (III) fluoride complexes exhibit solvatochromism with hypsochromic shifts upon moving to more strongly proton donating solvents. ${ }^{16}$ It has been suggested that this effect stems from a different radial dependence of the LF $\sigma$ and $\pi$-parameters for fluoride. However, DFT modeling of the interaction between neutral trifluorido complexes of $\mathrm{Cr}$ (III) and $\mathrm{Na}^{+}$in vacuum as well as in solution revealed a pronounced breakdown of the commonly assumed additivity of ligand-field contributions. ${ }^{9}$ Thus the actual decrease of the donor strength of fluoride upon ligation or solvation is more than compensated by an increased donation from the auxiliary amine, or as demonstrated here, imine ligands. The change in absorption spectrum results in isosbestic points suggesting only two spectroscopically distinct coordination environments of the chromium(III) as the Gd/Cr-ratio is increased.

The nature of the species in solution can be gauged by electrospray mass spectrometry of reaction mixtures before precipitation. For the tetranuclear compounds, this technique identifies fragments of composition $\left[\left\{\mathrm{CrF}_{2}(\text { phen })_{2}\right\}_{2} \mathrm{Ln}\right.$ $\left.\left(\mathrm{NO}_{3}\right)_{3} \operatorname{Ln}\left(\mathrm{NO}_{3}\right)_{4}\right]^{+}$and $\left[\mathrm{CrF}_{2}(\text { phen })_{2} \operatorname{Ln}\left(\mathrm{NO}_{3}\right)_{3}\right]^{+}$as the most prominent peaks in positive ion detection mode (Supporting Information, Figure S5.1) and $\left[\mathrm{CrF}_{2}(\text { phen })_{2} \mathrm{Ln}\right.$ $\left.\left(\mathrm{NO}_{3}\right)_{5}\right]^{-}$in negative ion detection mode for $\mathrm{Ln}=\mathrm{Ce}(\mathbf{1}), \mathrm{Sm}$ (4), and Gd (6). These ions are all likely fragments of the tetranuclear structures determined in the solid state and in agreement with the UV-vis spectroscopy points to extensive association in solution before precipitation.

Although very insoluble in acetonitrile, the isolated pentanuclear complexes $(10-13)$ can be redissolved to a small extent in this solvent, and the resulting solutions yield mass spectra, which can unambiguously be correlated to the solid state structure. Thus, three peaks are prominent in positive ion detected electrospray mass spectra of such solutions of 10-13 (cf. Supporting Information, Figure S6.1-S6.4). These peaks correspond to compositions of $\{M-$ $\mathrm{hfac}\}^{+},\{\mathrm{M}+\mathrm{Na}\}^{+}$, and $\left\{\mathrm{M}-\mathrm{LnF}_{2}(\mathrm{hfac})_{2}\right\}^{+}$, where $\mathrm{M}$ denotes the neutral pentanuclear cluster. The isotope pattern of the $\{M-$ hfac $\}^{+}$-peak for $\mathbf{1 2}$ is shown in Figure 5 together with that of the intact cluster plus a sodium ion. For both entities simulations corresponding to all bridging ligands being fluoride have been included. The perfect reproduction of the isotope pattern (as found for the isostructural clusters with different lanthanoid ions: 10, 12, and 13) rules out hydroxide ligands and demonstrate exclusive fluoride bridging in these clusters.

As the first examples of unsupported fluoride bridges between $3 \mathrm{~d}$ and $4 \mathrm{f}$ ions, the magnetic properties of these systems are of interest. The temperature dependencies of the $\chi T$ product for some of the tetranuclear square structures are shown in Figure 6. At high-temperature $(300 \mathrm{~K})$ the $\chi T$ values (2: $6.3 \mathrm{~cm}^{3} \mathrm{~K} \mathrm{~mol}^{-1}$; 3: $6.2 \mathrm{~cm}^{3} \mathrm{~K} \mathrm{~mol}^{-1}$; $4: 4.0 \mathrm{~cm}^{3} \mathrm{~K} \mathrm{~mol}^{-1}$ ) are in agreement with the values expected for two chromium(III) $(S=3 / 2, g \approx 2)$ and two lanthanoid ions $\left(\operatorname{Pr}:{ }^{3} \mathrm{H}_{4}, g_{J}=4 /\right.$ 5; Nd: $\left.{ }^{4} \mathrm{I}_{9 / 2}, g_{J}=8 / 11 ; \mathrm{Sm}:{ }^{6} \mathrm{H}_{5 / 2}, g_{J}=2 / 7\right)$. With decreasing temperature the value for $\chi T$ drops slightly for all compounds because of the progressive depopulations of ligand-field states (Stark sublevels).

Furthermore, for 2 a steep drop occurs below $\sim 10 \mathrm{~K}$ which is not observed for 3 and 4 where the $\chi T$ goes to a local minimum (at $\sim 13 \mathrm{~K}$ ) and then increases rapidly on lowering temperature. For TM compounds this behavior is a signature of a ferrimagnetic spin arrangement; however, in this case it may be a result of weak ferromagnetic $\mathrm{Ln}-\mathrm{Cr}(\mathrm{Ln}=\mathrm{Nd}, \mathrm{Sm})$ interactions masked by the above-mentioned decrease of $\chi T$ on descending temperature. Notably, this behavior parallels that observed for oxalate-bridged $\mathrm{Cr}-\mathrm{Ln}$ systems with the same lanthanoid ions. ${ }^{17}$ The magnetization curves do not show any 


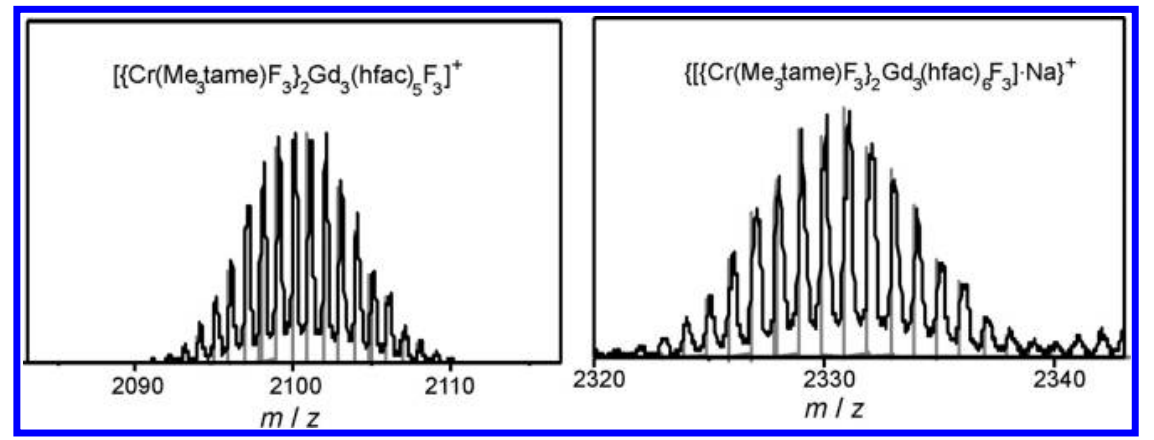

Figure 5. Extracts of the positive ion detected electrospray mass spectrum of 11 (black) together with simulations thereof (gray). Other important fragments observed for these complexes of all lanthanoid ions are $\left[\left\{\mathrm{Cr}\left(\mathrm{Me}_{3} \operatorname{tame}\right) \mathrm{F}_{3}\right\}_{2} \mathrm{Ln}_{2}(\mathrm{hfac})_{4} \mathrm{~F}\right]^{+}$and $\left[\left\{\mathrm{Cr}\left(\mathrm{Me} \mathrm{T}_{3} \operatorname{tame}\right) \mathrm{F}_{3}\right\}_{2} \mathrm{Ln}_{2}(\mathrm{hfac})_{5}\right]^{+}(\mathrm{see}$ Supporting Information).

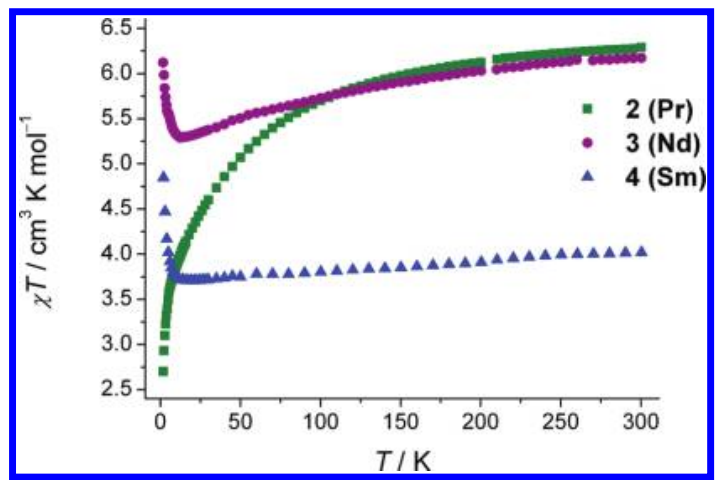

Figure 6. Temperature dependence of the $\chi T$ product for $\mathbf{2}, \mathbf{3}$, and $\mathbf{4}$. The expected high-temperature values calculated from the free ion Curie constants are 2: $6.88 \mathrm{~cm}^{3} \mathrm{~K} \mathrm{~mol}^{-1}, 3: 6.95 \mathrm{~cm}^{3} \mathrm{~K} \mathrm{~mol}^{-1}$, 4: 3.86 $\mathrm{cm}^{3} \mathrm{~K} \mathrm{~mol}^{-1}$.

signs of saturation at the highest available fields $H_{\mathrm{dc}} \leq 5 \mathrm{~T}$ (Supporting Information). This behavior is expected for systems with low-lying excited states and/or strong magnetic anisotropy. However, alternating current (ac) susceptibility measurements were conducted with and without a static field component and did not show any $\chi^{\prime \prime}$ signal ruling out the possibility that any of the compounds behave as singlemolecule magnets. This applies also to the dysprosium compound (8). Theoretical modeling of the magnetic properties of lanthanoid-containing clusters is inherently complicated because of the unknown ligand-field splittings and the exchange interactions which may be anisotropic in nature. For this reason, $\mathrm{Gd}^{3+}$, with its orbitally nondegenerate ${ }^{8} \mathrm{~S}_{7 / 2}$ ground state is the preferred lanthanoid ion for modeling of magnetic properties. In Figure 7 are shown the $\chi T$ products for the tetranuclear (6) and pentanuclear (11) gadolinium systems together with the modeling of these data by the spinHamiltonians of eq 1 :

For $\mathrm{Cr}_{2} \mathrm{Gd}_{2}(6)$ :

$$
\begin{aligned}
\hat{H}= & \mu_{\mathrm{B}} \mathbf{B} \cdot\left[g_{\mathrm{Cr}}\left(\hat{\mathbf{s}}_{\mathrm{Cr} 1}+\hat{\mathbf{S}}_{\mathrm{Cr} 2}\right)+g_{\mathrm{Gd}}\left(\hat{\mathbf{s}}_{\mathrm{Gd} 1}+\hat{\mathbf{s}}_{\mathrm{Gd} 2}\right)\right] \\
& +J_{\mathrm{Gd}-\mathrm{Cr}}\left(\hat{\mathbf{S}}_{\mathrm{Cr} 1} \cdot \hat{\mathbf{s}}_{\mathrm{Gd} 1}+\hat{\mathbf{S}}_{\mathrm{Cd} 1} \cdot \hat{\mathbf{s}}_{\mathrm{Cr} 2}+\hat{\mathbf{S}}_{\mathrm{Cr} 2} \cdot \hat{\mathbf{s}}_{\mathrm{Gd} 2}\right. \\
& \left.+\hat{\mathbf{S}}_{\mathrm{Gd} 2} \cdot \hat{\mathbf{S}}_{\mathrm{Cr} 1}\right)
\end{aligned}
$$

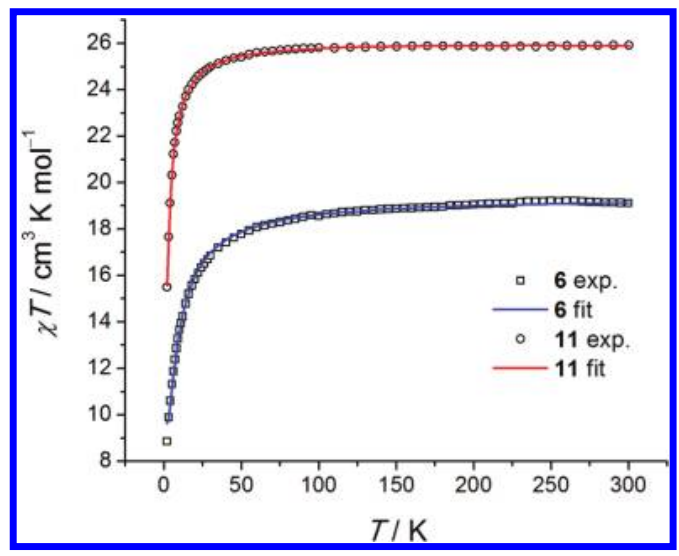

Figure 7. Fits of the $\chi T$ product for $6\left(\mathrm{Cr}_{2} \mathrm{Gd}_{2}\right.$-square $)$ and 11 $\left(\mathrm{Cr}_{2} \mathrm{Gd}_{3}\right.$-bipyramid) to the spin-Hamiltonian of eq 1 . The resulting parameter values are $6, J_{\mathrm{Cr}-\mathrm{Gd}}=0.71 \mathrm{~cm}^{-1} ; 11, J_{\mathrm{Cr}-\mathrm{Gd}}=0.14(0) \mathrm{cm}^{-1}$, $J_{\mathrm{Gd}-\mathrm{Gd}}=0.06(0) \mathrm{cm}^{-1}$. The $g$ factors were fixed to $g_{\mathrm{Cr}}=g_{\mathrm{Gd}}=2.0$.

For $\mathrm{Cr}_{2} \mathrm{Gd}_{3}(11)$ :

$$
\begin{aligned}
\hat{H}= & \mu_{\mathrm{B}} \mathbf{B} \cdot\left[g_{\mathrm{Cr}}\left(\hat{\mathbf{S}}_{\mathrm{Cr} 1}+\hat{\mathbf{S}}_{\mathrm{Cr} 2}\right)+g_{\mathrm{Gd}}\left(\hat{\mathbf{S}}_{\mathrm{Gd} 1}+\hat{\mathbf{S}}_{\mathrm{Gd} 2}+\hat{\mathbf{S}}_{\mathrm{Gd} 3}\right)\right] \\
& +J_{\mathrm{Cr}-\mathrm{Gd}}\left(\hat{\mathbf{S}}_{\mathrm{Cr} 1}+\hat{\mathbf{S}}_{\mathrm{Cr} 2}\right) \cdot\left(\hat{\mathbf{S}}_{\mathrm{Gd} 1}+\hat{\mathbf{S}}_{\mathrm{Gd} 2}+\hat{\mathbf{S}}_{\mathrm{Gd} 3}\right) \\
& +J_{\mathrm{Gd}-\mathrm{Gd}}\left(\hat{\mathbf{S}}_{\mathrm{Gd} 1} \cdot \hat{\mathbf{S}}_{\mathrm{Gd} 2}+\hat{\mathbf{S}}_{\mathrm{Gd} 1} \cdot \hat{\mathbf{S}}_{\mathrm{Gd} 3}+\hat{\mathbf{S}}_{\mathrm{Gd} 2} \cdot \hat{\mathbf{S}}_{\mathrm{Gd} 3}\right)
\end{aligned}
$$

The $g$ factors were fixed to $g_{\mathrm{Cr}}=g_{\mathrm{Gd}}=2.0$. The $\chi T$ and reduced magnetization $\left(M\right.$ vs $\mu_{\mathrm{B}} B / k_{\mathrm{B}} T$ ) data (Supporting Information) were fitted simultaneously. No zero-field splitting (ZFS) terms were included in the models but fitting of the $\chi T$ data only, gave the same $J$ parameter values indicating that the $\mathrm{Cr}(\mathrm{III})$ and $\mathrm{Gd}(\mathrm{III})$ magnetic anisotropies are vanishing. The fitting yields $J_{\mathrm{Gd}-\mathrm{Cr}}=0.71 \mathrm{~cm}^{-1}$ for 6 and $J_{\mathrm{Gd}-\mathrm{Cr}}=0.14(0) \mathrm{cm}^{-1}$ and $J_{\mathrm{Gd}-\mathrm{Gd}}=0.06(0) \mathrm{cm}^{-1}$ for $11 .^{18}$ The magnetic exchange coupling across the fluoride bridges is found to be comparable in magnitude $\left(0.14-0.71 \mathrm{~cm}^{-1}\right)$ to that observed for $3 \mathrm{~d}-\mathrm{Gd}$ interactions with other small bridges as cyanide ${ }^{19}$ or oxalate. $^{20}$ To the best of our knowledge, only one example of a Gd(III)$\mathrm{Cr}$ (III) cluster with solely monatomic bridges is reported. ${ }^{21}$ In this hydroxide bridged $\left\{\mathrm{GdCr}_{4}\right\}$ cluster the $\mathrm{Gd}-\mathrm{Cr}$ interaction is indeed antiferromagnetic, but its magnitude was not extracted. The very pronounced difference in magnitude of the coupling in $\mathbf{6}$ and $\mathbf{1 1}$ in conjunction with other results obtained by us, suggests that coupling decreases steeply with bending of the fluoride bridges. ${ }^{22}$

The quite weak couplings in $\mathbf{1 1}$ together with isotropic $\mathrm{Gd}(\mathrm{III})$ and $\mathrm{Cr}(\mathrm{III})$ with holohedrized octahedral coordination 
environment and concomitant small ZFS suggest that these systems should possess a large number of electronic states which are nearly degenerate with the ground state. This situation makes 11 a good candidate for the observation of a large Magneto-Caloric Effect (MCE), that is, the change of the magnetic entropy and related adiabatic temperature following a change in the applied magnetic field. This effect is at the basis of the magnetic refrigeration technique and therefore a large MCE is industrially in demand.

The magnetocaloric properties of $\mathbf{1 1}$ have been investigated by means of heat capacity $(C)$ experiments, which represent the most suitable probe for the indirect determination of $\mathrm{MCE} .^{2 \mathrm{a}}$ In Figure 8 is shown the experimental $C$, normalized to the gas

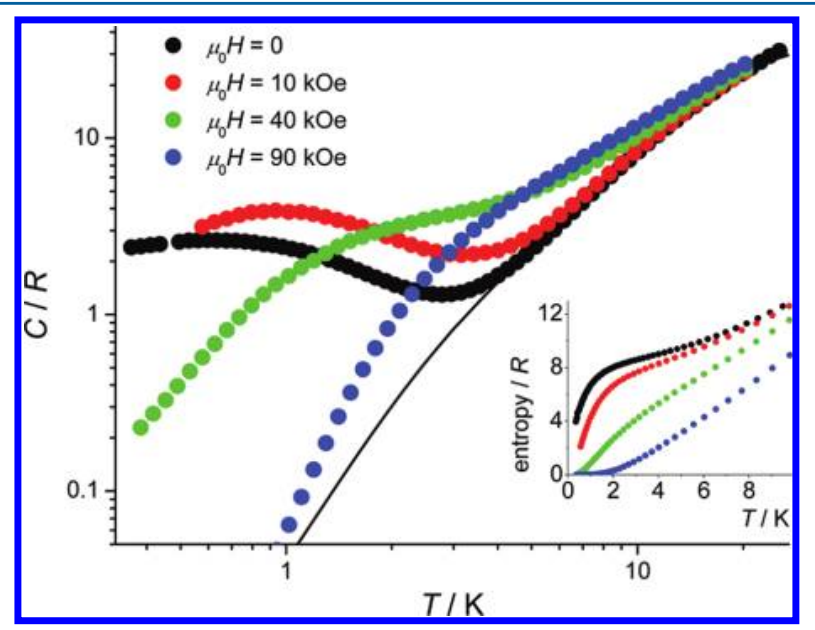

Figure 8. Temperature dependencies of the heat capacity $(C)$ of 11 normalized to the gas constant $R$, collected for $\mu_{0} H=0,10,40$, and 90 $\mathrm{kOe}$. Inset: temperature dependencies of the experimental entropy for several $H$, as obtained from the respective heat capacity data.

constant $R$, as function of temperature for selected applied magnetic fields $(H)$. At high temperatures the heat capacity is dominated by nonmagnetic contributions arising from thermal vibrations of the lattice, which can be modeled with the Debye function (solid line in Figure 8) yielding a value of $\Phi_{\mathrm{D}}=18.0 \mathrm{~K}$ for the Debye temperature, which is in the range of values observed for this class of molecular compounds. ${ }^{23}$ At low temperatures the heat capacity is dominated by an applied-field sensitive contribution, which shifts to higher temperatures by increasing $H$. From the experimental heat capacity, the temperature dependence of the entropy is obtained by integrating $\int C / T \mathrm{~d} T$, leading to the temperature dependencies of the entropy which are depicted in the inset of Figure 8 for the corresponding applied fields. In the cases of $\mu_{0} H=0$ and 10 $\mathrm{kOe}$, the lack of data points below approximately $0.3 \mathrm{~K}$ forced us to add a constant value to the corresponding entropy curves to match the limiting values at high temperature. This procedure is justified by the entropy calculations performed on the $C$ data obtained for higher fields, whose temperature dependencies are well within our experimentally accessible temperature window. As we shall see below, this procedure does not jeopardize our evaluation of the MCE of 11. We also notice that the so-obtained zero-field entropy increases sharply reaching an approximate value of $8 R$ at low temperatures. The $1 \mathrm{~K}<T<5 \mathrm{~K}$ temperature range is characterized by a slow increase of the zero-field entropy, passing from $\sim 8 R$ to $\sim 9 R$, respectively. Above roughly $5 \mathrm{~K}$, the zero-field entropy starts again to steadily increase because of the dominant lattice contribution (see Figure 8). The $8-9 R$ plateau could be understood assuming that, for this temperature range, all magnetic interactions are decoupled to large extent. Therefore, under this assumption, we expect the entropy to approach the maximum value for noninteracting single-ion spins, that is, $3 \times$ $R \ln \left(2 S_{\mathrm{Gd}}+1\right)+2 \times R \ln \left(2 S_{\mathrm{Cr}}+1\right)=9 R$, where $S_{\mathrm{Gd}}=7 / 2$ and $S_{\mathrm{Cr}}=3 / 2$, in good agreement with the experimental data.

From the temperature and field dependencies of the entropy (Figure 8 , inset), we can easily obtain the magnetic entropy change $\left(\Delta S_{m}\right)$ for selected applied field changes $(\Delta H)$. Note that the estimation of the lattice contribution is irrelevant for our calculations, since we deal with differences between total entropies at different magnetic field strengths. The resulting magnetic entropy changes are summarized in Figure 9. Besides

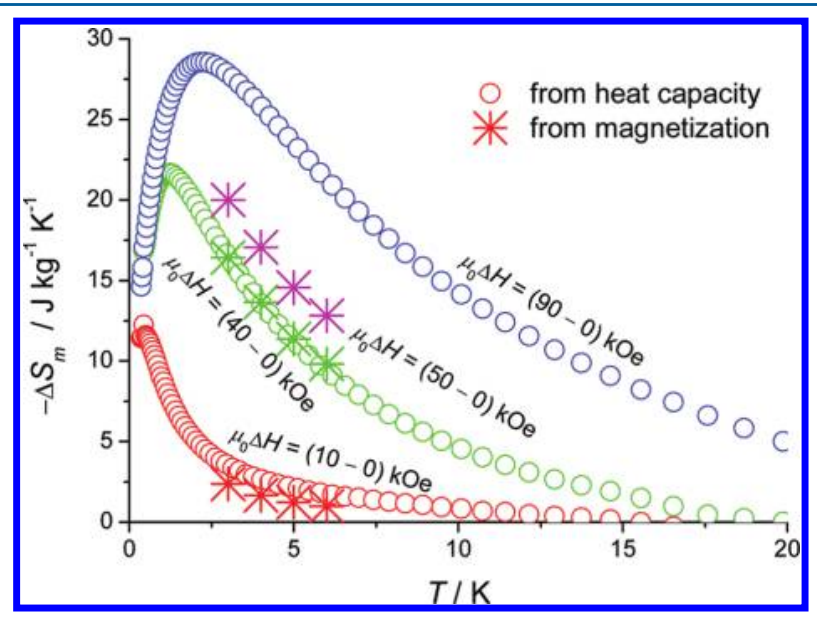

Figure 9. Temperature dependencies of the magnetic entropy change $\left(\Delta S_{m}\right)$ for 11 , as obtained from the respective heat capacity $(O)$ and magnetization $(*)$ data, for selected field changes $(\Delta H)$, as labeled.

heat capacity, magnetization $(M)$ data can also be employed for estimating the magnetic entropy change by making use of the Maxwell relation, $\Delta S_{\mathrm{m}}(T)=\int[\partial M / \partial T] \mathrm{d} H$. From the isothermal $M(H)$ curves (Supporting Information, Figure S3.4) the so-obtained temperature-dependencies of $\Delta S_{m}$ for $\mu_{0} \Delta H=$ 10, 40, and $50 \mathrm{kOe}$ are displayed in Figure 9. The nice agreement with the data obtained from $C$, proves that our experimental uncertainty in the low-temperature zero-field entropy does not affect the evaluation of the MCE of 11 .

We experimentally observe $-\Delta S_{m}$ to reach the maximum value of $28.7 \mathrm{~J} \mathrm{~kg}^{-1} \mathrm{~K}^{-1}$ for $T=2.2 \mathrm{~K}$ and $\Delta H=(90-0) \mathrm{kOe}$ (Figure 9). This is a remarkable MCE that sets 11 among the best performing molecular magnetic refrigerants recently reported in the literature. ${ }^{2,24}$ Our results suggest that 11 could potentially be employed as a magnetic refrigerant for the low-temperature range starting from $2 \mathrm{~K}$ and downward, that is, the starting temperature for an adiabatic demagnetization process. $^{2 a}$ This range is of considerable technological interest because it is easily reachable by pumping liquid ${ }^{4} \mathrm{He}$.

\section{CONCLUSION}

In conclusion, assembly of polynuclear lanthanoid complexes employing robust chromium(III)-fluoride complexes is a convenient route to small heterometallic complexes with fluoride bridges. These polynuclear complexes constitute the first examples of unsupported fluoride-bridges between a paramagnetic transition metal and a lanthanide ion. The propensity of fluoride for linear bridging established for 
polynuclear transition metal systems is manifest also in mixed 3d-4f systems. The resulting, structurally simple systems allowed for modeling of the magnetic properties and for the first quantification of magnetic coupling between $3 \mathrm{~d}$ and $4 \mathrm{f}$ centers across a fluoride bridge. This coupling was found to be numerically similar to that for cyanide or oxalate bridges, while the lack of systems with isoelectronic hydroxide or alkoxide bridges between chromium and gadolinium prevents direct comparison with these bridging ligands. The coupling appears to decrease pronouncedly with the bending of the fluoride bridges. This can be favorably exploited for achieving a large MCE, since a relatively large number of magnetic degrees of freedom become available at low temperature because of the low-lying excited spin states promoted by the weak coupling. The weakest intracluster interactions are achieved in the bipyramidally shaped $\left\{\mathrm{Gd}_{3} \mathrm{Cr}_{2}\right\}$ (11) complex. Indeed, for 11 we report a remarkably large MCE at low temperatures, which results also from the large net magnetic moment of the molecule, combined with its negligible anisotropy. Furthermore, $\mathbf{1 1}$ has a relatively large metal/ligand mass ratio that is an important advantage since the nonmagnetic ligands contribute passively to the MCE.

\section{EXPERIMENTAL SECTION}

Synthesis: Materials. $\mathrm{Ce}\left(\mathrm{NO}_{3}\right)_{3} \cdot 6 \mathrm{H}_{2} \mathrm{O}$ (Puriss. p.a., Fluka), $\mathrm{Pr}\left(\mathrm{NO}_{3}\right)_{3} \cdot \mathrm{H}_{2} \mathrm{O}$ (99.9\%, Alfa Aesar), $\mathrm{Nd}\left(\mathrm{NO}_{3}\right)_{3} \cdot 6 \mathrm{H}_{2} \mathrm{O}$ (99.9\%, Alfa Aesar), $\mathrm{Sm}\left(\mathrm{NO}_{3}\right)_{3} \cdot 6 \mathrm{H}_{2} \mathrm{O}$ (99.9\%, Alfa Aesar), $\mathrm{Eu}\left(\mathrm{NO}_{3}\right)_{3} \cdot 6 \mathrm{H}_{2} \mathrm{O}$ (99.9\%, Alfa Aesar), $\mathrm{Gd}\left(\mathrm{NO}_{3}\right)_{3} \cdot \mathrm{H}_{2} \mathrm{O}$ (99.9\%, Alfa Aesar), Tb$\left(\mathrm{NO}_{3}\right)_{3} \cdot 5 \mathrm{H}_{2} \mathrm{O}$ (99.9\%, Aldrich), Dy $\left(\mathrm{NO}_{3}\right)_{3} \cdot 5 \mathrm{H}_{2} \mathrm{O}$ (99.9\%, Alfa Aesar), $\mathrm{Ho}\left(\mathrm{NO}_{3}\right)_{3} \cdot 5 \mathrm{H}_{2} \mathrm{O}$ (99.9\%, Aldrich), $\mathrm{Er}\left(\mathrm{NO}_{3}\right)_{3} \cdot 5 \mathrm{H}_{2} \mathrm{O}(99.9 \%$, Alfa Aesar), $\mathrm{Yb}\left(\mathrm{NO}_{3}\right)_{3} \cdot \mathrm{H}_{2} \mathrm{O}$ (99.9\%, Alfa Aesar), 1,10-phenanthroline (Alfa Aesar), and the solvents MeOH (Lab Scan.), 2-methoxyethanol (ACS $99.3+\%$, Alfa Aesar) were used as received.

cis- $\left.\left[\mathrm{CrF}_{2} \text { (phen }\right)_{2}\right] \mathrm{NO}_{3}$ was synthesized using a slightly modified version of the method for synthesis of perchlorate salt. ${ }^{8 \mathrm{a}}$ trans$\left[\mathrm{CrF}_{2}(\text { py })_{4}\right] \mathrm{NO}_{3}(0.13 \mathrm{~mol})$ and 1,10-phenanthroline $(0.25 \mathrm{~mol})$ were refluxed in 2 -methoxyethanol $(200 \mathrm{~mL})$ for $1 \mathrm{~h}$. The resulting pink-orange product was collected by filtration and washed repeatedly with EtOH $(99 \%, 4 \times 100 \mathrm{~mL})$. Yield: $\sim 85 \%$. fac$\left[\mathrm{CrF}_{3}\left(\mathrm{Me}_{3} \mathrm{tame}\right)\right] \cdot \mathrm{H}_{2} \mathrm{O}$ and $\mathrm{fac}$ - $\left[\mathrm{CrF}_{3}\left(\mathrm{Me}_{3} \mathrm{tacn}\right)\right]$ were synthesized by the general protocol applied in the above reference using 2methoxyethanol and DMF as solvents, respectively. Yields ranged from 65 to $75 \%$. $\left[\mathrm{Ln}(\mathrm{hfac})_{3}\left(\mathrm{H}_{2} \mathrm{O}\right)_{2}\right](\mathrm{Ln}=\mathrm{Sm}, \mathrm{Gd}, \mathrm{Ho}, \mathrm{Y})$ was synthesized as described in literature. ${ }^{25}$

General Synthesis of $\left\{\left[\mathrm{CrF}_{2}(\text { phen })_{2}\right]\left[\operatorname{Ln}\left(\mathrm{NO}_{3}\right)_{4}\right]\right\}_{2}$. All of the tetranuclear clusters were prepared by the same general protocol given here. A solution of cis- $\left[\mathrm{CrF}_{2}(\mathrm{phen})_{2}\right] \mathrm{NO}_{3}(0.82 \mathrm{mmol})$ in $\mathrm{MeOH}(20$ $\mathrm{mL}$ ) was stirred at RT for $30 \mathrm{~min}$ and filtered twice through syringe filters with pore size $0.45 \mu \mathrm{m}$. This resulting solution (I) was diluted with an additional $20 \mathrm{~mL}$ of $\mathrm{MeOH}$ (for prep. of $\mathrm{Pr}$ and $\mathrm{Nd}$ compounds) or $10 \mathrm{~mL}$ of $\mathrm{MeOH}$ (for the remaining lanthanoids). A second solution (II) was made up of $\operatorname{Ln}\left(\mathrm{NO}_{3}\right)_{3} \cdot \mathrm{aq}(0.81 \mathrm{mmol})$ in $\mathrm{MeOH}(10 \mathrm{~mL})$. The two solutions were mixed and left for crystallization for $24 \mathrm{~h}$ at RT. Yields do not improve by preparation at $0{ }^{\circ} \mathrm{C}$. The resulting mass of red crystals and white powder (the ratio between these depends on lanthanoid in question) was loosened and brought into suspension. Crystals were harvested by decantation of the byproduct in suspension. The crystals were washed repeatedly with $\mathrm{MeOH}$ by decantation until all the pale colored byproduct was removed, and dried on a sintered glass filter in a dynamic vacuum. Upon drying, solvent loss causes the crystals to lose their luster. A faster precipitation of the product in microcrystalline form can be achieved for $\mathrm{Pr}, \mathrm{Nd}$, and $\mathrm{Sm}$ by not adjusting the volume of solution I with additional $\mathrm{MeOH}$. The suspension of byproduct in $\mathrm{MeOH}$ was transferred to centrifuge tubes and centrifuged, washed thoroughly with $\mathrm{MeOH}$, and dried in a dynamic vacuum.
Yields and analytical data for the individual compounds are given below. Note, that drying has resulted in partial solvent loss. For all compounds except that of $\mathrm{Gd}$, the calculated values are given for the solvent free composition.

$\left\{\left[\mathrm{CrF}_{2}(\text { phen })_{2}\right]\left[\mathrm{Ce}\left(\mathrm{NO}_{3}\right)_{4}\right]\right\}_{2}$ (1): Yield: $74 \%$ of theoretical based on $\mathrm{Ce}^{\text {III. }}$. Elemental analysis calcd (\%) for $\mathrm{H}_{32} \mathrm{C}_{48} \mathrm{~N}_{16} \mathrm{O}_{24} \mathrm{~F}_{4} \mathrm{Cr}_{2} \mathrm{Ce}_{2}: \mathrm{H}$ 1.92, C 34.38, N 13.36; found: H 1.72, C 32.83, N 12.36. By-product: None.

$\left\{\left[\mathrm{CrF}_{2}(\text { phen })_{2}\right]\left[\operatorname{Pr}\left(\mathrm{NO}_{3}\right)_{4}\right]\right\}_{2}$ (2):Yield: $82 \%$ of theoretical based on $\mathrm{Pr}^{\mathrm{III}}$. Elemental analysis calcd (\%) for $\mathrm{H}_{32} \mathrm{C}_{48} \mathrm{~N}_{16} \mathrm{O}_{24} \mathrm{~F}_{4} \mathrm{Cr}_{2} \mathrm{Pr}_{2}: \mathrm{H}$ 1.92, C 34.34, N 13.35; found: H 1.94, C 33.44, N 12.44. By-product: Present, but small amount.

$\left\{\left[\mathrm{CrF}_{2}(\text { phen })_{2}\right]\left[\mathrm{Nd}\left(\mathrm{NO}_{3}\right)_{4}\right]\right\}_{2}$ (3): Yield: $87 \%$ of theoretical based on $\mathrm{Nd}^{\mathrm{III}}$. Elemental analysis calcd (\%) for $\mathrm{H}_{32} \mathrm{C}_{48} \mathrm{~N}_{16} \mathrm{O}_{24} \mathrm{~F}_{4} \mathrm{Cr}_{2} \mathrm{Nd}_{2}$ : $\mathrm{H}$ 1.91, C 34.21, N 13.30; found: H 2.05, C 34.24, N 12.69. By-product: Present, but small amount.

$\left\{\left[\mathrm{CrF}_{2}(\text { phen })_{2}\right]\left[\mathrm{Sm}\left(\mathrm{NO}_{3}\right)_{4}\right]\right\}_{2}$ (4): Yield: $87 \%$ of theoretical based on $\mathrm{Sm}^{\mathrm{III}}$. Elemental analysis calcd (\%) for $\mathrm{H}_{32} \mathrm{C}_{48} \mathrm{~N}_{16} \mathrm{O}_{24} \mathrm{~F}_{4} \mathrm{Cr}_{2} \mathrm{Sm}_{2}: \mathrm{H}$ 1.90, C 33.96, N 13.20; found: H 2.08, C 33.79, N 12.52. By-product: $0.035 \mathrm{~g}$ (Analysis: Found (\%): H, 1.62; C, 24.41; N, 7.99).

$\left.\left\{\left[\mathrm{CrF}_{2} \text { (phen }\right)_{2}\right]\left[\mathrm{Eu}\left(\mathrm{NO}_{3}\right)_{4}\right]\right\}_{2}$ (5): Yield: $37 \%$ of theoretical based on $\mathrm{Eu}^{\text {III }}$. Elemental analysis calcd (\%) for $\mathrm{H}_{32} \mathrm{C}_{48} \mathrm{~N}_{16} \mathrm{O}_{24} \mathrm{~F}_{4} \mathrm{Cr}_{2} \mathrm{Eu}_{2}: \mathrm{H}$ 1.90, C 33.90, N 13.18; found (\%): H 1.97, C 33.59, N 12.10. Byproduct: $0.070 \mathrm{~g}$ (Analysis: Found (\%): H, 1.76; C, 26.85; N, 9.16).

$\left\{\left[\mathrm{CrF}_{2}(\text { phen })_{2}\right]\left[\mathrm{Gd}\left(\mathrm{NO}_{3}\right)_{4}\right]\right\}_{2} \cdot \mathrm{CH}_{3} \mathrm{OH} \cdot \mathrm{H}_{2} \mathrm{O}(6)$ : Yield: $27 \%$ of theoretical based on $\mathrm{Gd}^{\mathrm{III}}$. Elemental analysis calcd (\%) for $\mathrm{H}_{38} \mathrm{C}_{49} \mathrm{~N}_{16} \mathrm{O}_{26} \mathrm{~F}_{4} \mathrm{Cr}_{2} \mathrm{Gd}_{2}: \mathrm{H}$ 2.17, C 33.41, N 12.72; found: $\mathrm{H}$ 2.06, C 33.53, N 12.25. By-product: 0.05 g (Analysis: Found (\%): H, 1.64; C, 25.02; N, 7.99).

$\left.\left\{\left[\mathrm{CrF}_{2} \text { (phen }\right)_{2}\right]\left[\mathrm{Tb}\left(\mathrm{NO}_{3}\right)_{4}\right]\right\}_{2}(7)$ : Yield: $5.5 \%$ of theoretical based on $\mathrm{Tb}^{\mathrm{III}}$. Elemental analysis calcd (\%) for $\mathrm{H}_{32} \mathrm{C}_{48} \mathrm{~N}_{16} \mathrm{O}_{24} \mathrm{~F}_{4} \mathrm{Cr}_{2} \mathrm{~Tb}_{2}: \mathrm{H}$ 1.88, C 33.62, N 13.07; found: $\mathrm{H} 1.85$, C 33.07, N 12.06. By-product: 0.082 g (Analysis: Found (\%): H, 1.63; C, 24.41; N, 7.81).

$\left\{\left[\mathrm{CrF}_{2}(\text { phen })_{2}\right]\left[\mathrm{Dy}\left(\mathrm{NO}_{3}\right)_{4}\right]\right\}_{2}(8)$ : Yield: $1.8 \%$ of theoretical based on Dy ${ }^{\text {III }}$. Elemental analysis calcd (\%) for $\mathrm{H}_{32} \mathrm{C}_{48} \mathrm{~N}_{16} \mathrm{O}_{24} \mathrm{~F}_{4} \mathrm{Cr}_{2} \mathrm{Eu}_{2}: \mathrm{H}$ 1.87, C 33.48, N, 13.02; found: $\mathrm{H} 1.79, \mathrm{C} 32.09, \mathrm{~N}$ 12.19. The isolated crystalline product is contaminated with a crystalline impurity (cf. Figure 1) By-product: $0.097 \mathrm{~g}$ (Analysis: Found (\%): H, 1.67; C, 24.36; N, 7.81).

$\left\{\left[\mathrm{CrF}_{2}(\text { phen })_{2}\right]\left[\mathrm{Ho}\left(\mathrm{NO}_{3}\right)_{4}\right]\right\}_{2}(9)$ : Yield: Few crystals. By-product: 0.107 g (Analysis: Found (\%): H, 1.61; C, 24.09; N, 7.75).

Attempted synthesis of $\left\{\left[\mathrm{CrF}_{2}(\mathrm{phen})_{2}\right]\left[\mathrm{Er}\left(\mathrm{NO}_{3}\right)_{4}\right]\right\}_{2}$ : Yield: None. By-product: $0.093 \mathrm{~g}$ (Analysis: Found (\%): H, 1.64; C, 23.72; N, 7.65).

Attempted synthesis of $\left.\left\{\left[\mathrm{CrF}_{2} \text { (phen }\right)_{2}\right]\left[\mathrm{Yb}\left(\mathrm{NO}_{3}\right)_{4}\right]\right\}_{2}$ : Yield: None. By-product: $0.016 \mathrm{~g}$ (Analysis: Found (\%): H, 1,24; C, 13.36; N, 5.11).

Synthesis of $\left\{\left[\mathrm{CrF}_{2}(\mathrm{bpy})_{2}\right]\left[\mathrm{Ln}\left(\mathrm{NO}_{3}\right)_{4}\right]\right\}_{2}(\mathrm{Ln}=\mathrm{Nd}, \mathrm{Sm}, \mathrm{Eu}, \mathrm{Gd})$. This synthesis proceeds similarly as for the phenanthroline analogues. Details are provided in the Supporting Information.

Synthesis of $\left[\left\{\mathrm{CrF}_{3}\left(\mathrm{Me}_{3} \text { tame }\right)\right\}_{2} \mathrm{Ln}_{3}(\mathrm{hfac})_{6}(\mu-\mathrm{F})_{3}\right] \cdot 7 \mathrm{CH}_{3} \mathrm{CN}$ ( $\mathrm{Ln}$ = Sm (10), Gd (11), Ho (12), Yb(13)). [ $\left.\mathrm{Ln}(\mathrm{hfac})_{3}\left(\mathrm{H}_{2} \mathrm{O}\right)_{2}\right](0.61$ $\mathrm{mmol})$ was dissolved in $\mathrm{MeCN}(5 \mathrm{~mL})$, and the resulting solution was added to a suspension of $\mathrm{fac}$ - $\left[\mathrm{CrF}_{3}\left(\mathrm{Me}_{3} \mathrm{tame}\right)\right] \cdot 3 \mathrm{H}_{2} \mathrm{O}(0.41 \mathrm{mmol})$ in $\mathrm{MeCN}(5 \mathrm{~mL})$. The mixture was stirred for $2 \mathrm{~min}$ and filtered. The filtrate was kept for $24 \mathrm{~h}$ to yield red-purple, X-ray quality crystals. Yields: $20-25 \%$ (based on Ln). When the crystals are removed from the mother liquor, desolvation takes place and the crystals deteriorate. Thoroughly dried products yield the following elemental analyses: 10: calcd (\%) for $\mathrm{H}_{48} \mathrm{C}_{44} \mathrm{~N}_{6} \mathrm{O}_{12} \mathrm{~F}_{45} \mathrm{Cr}_{2} \mathrm{Sm}_{3}: \mathrm{H}$ 2.14, C 23.35, N 3.71; found: $\mathrm{H}$ 2.12, $\mathrm{C} 23.15, \mathrm{~N}$ 3.38. 11: calcd (\%) for $\mathrm{H}_{48} \mathrm{C}_{44} \mathrm{~N}_{6} \mathrm{O}_{12} \mathrm{~F}_{45} \mathrm{Cr}_{2} \mathrm{Gd}_{3}$ : $\mathrm{H}$ 2.12, C 23.14, N 3.68; found: $\mathrm{H} 2.07, \mathrm{C}$ 23.12, N 3.37. 12: calcd (\%) for $\mathrm{H}_{48} \mathrm{C}_{44} \mathrm{~N}_{6} \mathrm{O}_{12} \mathrm{~F}_{45} \mathrm{Cr}_{2} \mathrm{Ho}_{3}$ : $\mathrm{H} 2.10$, C 22.91, N 3.64; found: $\mathrm{H} 1.92, \mathrm{C} 23.17, \mathrm{~N} 3.52$. 13: calcd (\%) for $\mathrm{H}_{48} \mathrm{C}_{44} \mathrm{~N}_{6} \mathrm{O}_{12} \mathrm{~F}_{45} \mathrm{Cr}_{2} \mathrm{Yb}_{3}: \mathrm{H}$ 2.08, C 22.68, N 3.61; found: $\mathrm{H} 1.98, \mathrm{C}$ 22.60, N 3.30.

Synthesis of $\left[\left\{\mathrm{CrF}_{3}\left(\mathrm{Me}_{3} \mathrm{tacn}\right)\right\}_{2} \mathrm{Nd}_{3}\left(\mathrm{NO}_{3}\right)_{8}\left(\mu_{3}-\mathrm{F}\right)\left(\mathrm{H}_{2} \mathrm{O}\right)\right] \cdot 6 \mathrm{CH}_{3} \mathrm{CN}$ (14). A solution of $\mathrm{fac}$ - $\left[\mathrm{CrF}_{3}\left(\mathrm{Me}_{3} \mathrm{tacn}\right)\right](0.100 \mathrm{~g}, 0.36 \mathrm{mmol})$ in $\mathrm{MeCN}(10 \mathrm{~mL})$ was allowed to diffuse through a porous glass frit (D4) into a solution of $\mathrm{Nd}\left(\mathrm{NO}_{3}\right)_{3} \cdot 6 \mathrm{H}_{2} \mathrm{O}(0.205 \mathrm{~g}, 0.47 \mathrm{mmol})$ in 
$\mathrm{MeCN}(20 \mathrm{~mL})$ at $5{ }^{\circ} \mathrm{C}$. Over a period of days pink rod-shaped crystals develop. These are very often hollow and encapsulate some of the mother liquor. Upon drying they lose solvent and crumble. The best elemental analyses were obtained by gently crushing of the crystalline product, repeated washing with $\mathrm{MeCN}$, and storage below 0 ${ }^{\circ} \mathrm{C}$. Elemental analysis calcd (\%) for $\mathrm{H}_{62} \mathrm{C}_{30} \mathrm{~N}_{20} \mathrm{O}_{25} \mathrm{~F}_{7} \mathrm{Cr}_{2} \mathrm{Nd}_{3}$ : $\mathrm{H} 3.53$, C 20.33, N 15.80; found: H 3.58, C 20.08, N 15.47.

Physical Measurements. Elemental analysis for $\mathrm{C}, \mathrm{H}$, and $\mathrm{N}$ was performed with a CE Instrument: FLASH 1112 series EA, at the microanalytical laboratory, University of Copenhagen. UV/vis spectra were recorded on a Perkin-Elmer, Lambda $2 \mathrm{UV} /$ vis spectrophotometer. Electrospray mass spectra were recorded on a micromass QTof spectrometer employing cone-voltages in the range $20-45 \mathrm{~V}$ from solutions with concentrations in the nominal range 5-50 $\mu \mathrm{M}$.

X-ray Crystallography. All single-crystal X-ray diffraction data were collected at $122(1) \mathrm{K}$ on a Nonius KappaCCD area-detector diffractometer, equipped with an Oxford Cryostreams low-temperature device, using graphite-monochromated $\mathrm{MoK} \alpha$ radiation $(\lambda=0.71073$ $\AA$ ). The structures were solved using direct methods (SHELXS97) and refined using the SHELXL97 software package. ${ }^{26}$ Crystals suitable for $\mathrm{X}$-ray diffraction were obtained direct from the synthetic procedure. All non-hydrogen atoms were refined anisotropically. Hydrogen atoms were located in the difference Fourier map and refined isotropically and constrained riding their parent atom in a fixed geometry. In 3 and 6 the water of crystallization is located on a crystallographic 4-fold axis, and the hydrogen atoms could not be located. Crystals of $\mathbf{1 1}$ and $\mathbf{1 2}$ were extremely fragile, thin plates, which had to be transferred directly from the mother liquor to mineral oil to prevent rapid solvent loss. Hence, only low quality data could be obtained for $\mathbf{1 1}$ and 12; in both structures the hfac ${ }^{-}$ligands coordinated to one of the Ln-atoms are disordered. The disorder was resolved by refining the hfac ${ }^{-}$ligands in two positions, equally populated, with one set angled $69^{\circ}$ with respect to the other. Crystal structure and refinement data for 6, 11, 12, 14, and $\left\{\left[\mathrm{CrF}_{2}(\text { bpy })_{2}\right]\left[\mathrm{Nd}\left(\mathrm{NO}_{3}\right)_{4}\right]\right\}_{2}$ are summarized in Supporting Information, Tables S1a and S1b. CCDC reference numbers: 837951 (6), 838473 (11), 838474 (12), 861406 (14), and 860725 $\left(\left\{\left[\mathrm{CrF}_{2}(\mathrm{bpy})_{2}\right]\left[\mathrm{Nd}\left(\mathrm{NO}_{3}\right)_{4}\right]\right\}_{2}\right)$. These data can be obtained free of charge from The Cambridge Crystallographic Data Centre via www. ccdc.cam.ac.uk/data_request/cif. The molecular structure diagrams were produced with the Mercury program ver. 2.4 from The Cambridge Crystallographic Data Center. Powder X-ray crystallographic data were collected on a STOE Stadi-P powder diffractometer equipped with PSD-detector using $\mathrm{Cu}(1.54060 \AA)$ radiation monochromated with curved germanium. Data were subtracted a background by use of the STOE WinXPOW software ver. 1.10. Theoretical powder diffractograms were generated from the single crystal structure by use of the software "Mercury CSD 2.2" from The Cambridge Crystallographic Data Center. ${ }^{27}$

Magnetic Measurements. The magnetic measurements were conducted on a MPMS-XL Quantum-Design SQUID magnetometer located at University of Copenhagen. All measurements were performed on polycrystalline samples immobilized in a frozen $n$ eicosane matrix to avoid torqueing. The susceptibilities were corrected for diamagnetic contributions from the sample holder, $n$-eicosane, and the sample by means of Pascal's constants. Alternating current (ac) susceptibility measurements were measured with various frequencies in the range $1-1500 \mathrm{~Hz}$ with an ac field amplitude of 3 Oe with and without an applied static field $\left(H_{\mathrm{dc}}<2 \mathrm{kOe}\right)$. The modeling was performed with MagProp ${ }^{28}$ and home-written software. Heat capacity measurements using the relaxation method down to $\sim 0.3 \mathrm{~K}$ on powder samples were carried out by means of a commercial setup for the $0<B_{0}<9$ T magnetic field range.

\section{ASSOCIATED CONTENT}

\section{S Supporting Information}

Table of crystallographic data for 6, 11, 12, and 14 (Table S1a) as well as for $\left\{\left[\mathrm{CrF}_{2}(\text { bpy })_{2}\right]\left[\mathrm{Nd}\left(\mathrm{NO}_{3}\right)_{4}\right]\right\}_{2}$ (Table S1b). Powder diffraction data for $\left\{\left[\mathrm{CrF}_{2}(\mathrm{bpy})_{2}\right]\left[\mathrm{Ln}\left(\mathrm{NO}_{3}\right)_{4}\right]\right\}_{2}$ ( $\mathrm{Ln}$ $=\mathrm{Pr}, \mathrm{Nd}, \mathrm{Sm}, \mathrm{Eu}, \mathrm{Gd})$. Magnetization data for compounds 2, 3,
4, and 11. Syntheses and analytical data for $\left\{\left[\mathrm{CrF}_{2}(\mathrm{bpy})_{2}\right]\right.$ $\left.\left[\mathrm{Ln}\left(\mathrm{NO}_{3}\right)_{4}\right]\right\}_{2}(\mathrm{Ln}=\mathrm{Nd}, \mathrm{Sm}, \mathrm{Eu}, \mathrm{Gd})$. Electrospray mass spectra for compounds 1,4 , and 6 as well as for compounds 10-13. This material is available free of charge via the Internet at http://pubs.acs.org.

\section{AUTHOR INFORMATION}

\section{Corresponding Author}

*Fax: +45 35320212. E-mail: bendix@kiku.dk.

Notes

The authors declare no competing financial interest.

\section{ACKNOWLEDGMENTS}

J.B. and H.W. thank the Danish Research Councils for support under Grant FNU: 272-08-0491. S.P. thanks FNU Sapere Aude (Grant 10-081659).

\section{REFERENCES}

(1) (a) Sessoli, R.; Gatteschi, G.; Caneschi, A.; Novak, M. A. Nature 1993, 45, 141-143. (b) Gatteschi, D.; Caneschi, A.; Pardi, L.; Sessoli, R. Science 1994, 265, 1054-1058. (c) Ishikawa, N.; Sugita, M.; Ishikawa, T.; Koshihara, S.; Kaizu, Y. I. Am. Chem. Soc. 2003, 125, 8694-8695. (d) Ishikawa, N. Polvhedron 2007, 26, 2147-2153. (e) Milios, C. J.; Vinslava, A.; Wernsdorfer, W.; Moggach, S.; Parsons, S.; Perlepes, S. P.; Christou, G.; Brechin, E. K. I. Am. Chem. Soc. 2007, 129, 2754-2755. (f) AlDamen, M. A.; Clemente-Juan, J. M.; Coronado, E.; Marti-Gastaldo, C.; Gaita-Arino, A. I. Am. Chem. Soc. 2008, 130, 8874-8875. (g) Sessoli, R.; Powell, A. K. Coord. Chem. Rev. 2009, 253, 2328-2341. (h) Sorace, L.; Benelli, C.; Gatteschi, D. Chem. Soc. Rev. 2011, 40, 3092-3104. (i) Rinehart, J. D.; Long, J. R. Chem. Sci. 2011, 2, 2078-2085. (j) Jiang, S.-D.; Wang, B.-W.; Sun, H.-L.; Wang, Z.-M.; Gao, S. I. Am. Chem. Soc. 2011, 133, 4730-4733. (k) Hewitt, I. J.; Tang, J.; Madhu, N. T.; Anson, C. E.; Lan, Y.; Luzon, J.; Etienne, M.; Sessoli, R.; Powell, A. K. Angew. Chem. Int. Ed. 2010, 49, 6352-6356. (1) Lin, P.-H.; Burchell, T. J.; Ungur, L.; Chibotaru, L. F.; Wernsdorfer, W.; Murugesu, M. Angew. Chem. Int. Ed. 2009, 48, 9489-9492. (m) Blagg, R. J.; Muryn, C. A.; McInnes, E. J. L.; Tuna, F.; Winpenny, R. E. P. Anoew. Chem. Int. Ed. 2011, 50, 6530-6533. (2) (a) Evangelisti, M.; Brechin, E. K. Dalton Trans. 2010, 39, 46724676. (b) Karotsis, G.; Evangelisti, M.; Dalgarno, S. J.; Brechin, E. K. Angew. Chem. Int. Ed. 2009, 48, 9928-9921. (c) Sharples, J. W.; Zheng, Y.-Z.; Tuna, F.; McInnes, E. J. L. Chem. Commun. 2011, 47, 7650-7652. (d) Evangelisti, M.; Roubeau, O.; Palacios, E.; Camón, A.; Hooper, T. N.; Brechin, E. K.; Alonso, J. I. Angew. Chem., Int. Ed. 2011, 50, 6606-6609. (e) Zheng, Y.-Z.; Evangelisti, M.; Winpenny, R. E. P. Angew. Chem. Int. Ed. 2011, 50, 3692-3695. (f) Peng, J.-B.; Zhang, Q.-C.; Kong, X.-J.; Ren, Y.-P.; Long, L.-S.; Huang, R.-B.; Zheng, L.-S.; Zheng, Z. Angew. Chem. Int. Ed. 2011, 50, 10649-10652. Langley, S. K.; Chilton, N.; Moubaraki, B.; Hooper, T.; Brechin, E. K.; Evangelisti, M.; Murray, K. S. Chem. Sci. 2011, 2, 1166-1169.

(3) (a) Winpenny, R. E. P. Chem. Soc. Rev. 1998, 27, 447-452. (b) Benelli, C.; Gatteschi, D. Chem. Rev. 2002, 102, 2369-2388. (c) Andruh, M.; Costes, J.-P.; Diaz, C.; Gao, S. Inorg. Chem. 2009, 48, 3342-3359. (d) Osa, S.; Kido, T.; Matsumoto, N.; Re, N.; Pochaba, A.; Mrozinski, J. I. Am. Chem. Soc. 2004, 126, 420-421. (e) Mishra, A.; Wernsdorfer, W.; Abboud, K. A.; Christou, G. I. Am. Chem. Soc. 2004, 126, 15648-15649. (f) Mori, F.; Ishida, T.; Nogami, T. Polvhedron 2005, 24, 2588-2592. (g) Costes, J.-P.; Dahan, F.; Wernsdorfer, W. Inorg. Chem. 2006, 45, 5-7. (h) Aronica, C.; Pilet, G.; Chastanet, G.; Wernsdorfer, W.; Jacquot, J. F.; Luneau, D. Angew. Chem. Int. Ed. 2006, 45, 4659-4662. (i) Chandrasekhar, V.; Pandian, B. M.; Azhakar, R.; Vittal, J. J.; Clérac, R. Inorg. Chem. 2007, 46, 5140-5142. (j) Mereacre, V.; Ako, A. M.; Clérac, R.; Wernsdorfer, W.; Hewitt, I. J.; Anson, C. E.; Powell, A. K. Chem.-Eur. I. 2008, 14, 3577-3584. (k) Ke, H.; Xu, G.-F.; Zhao, L.; Tang, J.; Zhang, X.-Y.; Zhang, H.-J. Chem.-Eur. I. 2009, 15, 10335-10338. (1) Rinck, J.; Novitchi, G.; Van den Heuvel, W.; Ungur, L.; Lan, Y.; Wernsdorfer, W.; Anson, C. 
E.; Chibotaru, L. F.; Powell, A. K. Angew. Chem., Int. Ed. 2010, 49, 7583-7587. (m) Yamaguchi, T.; Costes, J.-P.; Kishima, Y.; Kojima, M.; Sunatsuki, Y.; Bréfuel, N.; Tuchagues, J.-P.; Vendier, L.; Wernsdorfer, W. Inorg. Chem. 2010, 49, 9125-9135. (n) Schray, D.; Abbas, G.; Lan, Y.; Mereacre, V.; Sundt, A.; Dreiser, J.; Waldmann, O.; Kostakis, G. E.; Anson, C. E.; Powell, A. K. Angew. Chem., Int. Ed. 2010, 49, 5185-5188. (o) Mereacre, V.; Baniodeh, A.; Anson, C. E.; Powell, A. K. J. Am. Chem. Soc. 2011, 133, 15335-15337. (p) Papatriantafyllopoulou, C.; Abboud, K. A.; Christou, G. Inorg. Chem. 2011, 50, 8959-8966.

(4) Perdih, F.; Demsar, A.; Pevec, A.; Petricek, S.; Leban, I.; Giester, G.; Sieler, J.; Roesky, H. W. Polvhedron 2001, 20, 1967-1971.

(5) Pevec, A.; Mrak, M.; Demsar, A.; Petricek, S.; Roesky, H. W. Polyhedron 2003, 22, 575-579.

(6) McRobbie, A.; Sarwar, A. R.; Yeninas, S.; Nowell, H.; Baker, M. L.; Allan, D.; Luban, M.; Muryn, C. A.; Pritchard, R. G.; Prozorov, R.; Timco, G.; Tuna, F.; Whitehead, G. F. S.; Winpenny, R. E. P. Chem. Commun. 2011, 47, 6251-6253.

(7) Pearson, R. G. I. Am. Chem. Soc. 1963, 85, 3533-3539.

(8) (a) Glerup, J.; Josephsen, J.; Michelsen, K.; Pedersen, E.; Schäffer, C. E. Acta Chem. Scand. 1970, 24, 247-254. (b) Andersen, P.; Døssing, A.; Glerup, J.; Rude, M. Acta Chem. Scand. 1990, 44, 346352. (c) Böttcher, A.; Elias, H.; Glerup, J.; Neuburger, M.; Olsen, C. E.; Paulus, H.; Springborg, J.; Zehnder, M. Acta Chem. Scand. 1994, 48, 967-980. (d) Böttcher, A.; Elias, H.; Glerup, J.; Neuburger, M.; Olsen, C. E.; Springborg, J.; Weihe, H.; Zehnder, M. Acta Chem. Scand. 1994, 48, 981-988.

(9) Birk, T.; Magnussen, M. J.; Piligkos, S.; Weihe, H.; Holten, A.; Bendix, J. I. Fluorine Chem. 2010, 131, 898-906.

(10) Dreiser, J.; Pedersen, K. S.; Piamonteze, C.; Rusponi, S.; Salman, Z.; Ali, Md. E.; Schau-Magnussen, M.; Thuesen, C. Aa.; Piligkos, S.; Weihe, H.; Mutka, H.; Waldmann, O.; Oppeneer, P.; Bendix, J.; Nolting, F.; Brune, H. Chem. Sci. 2012, 3, 1024-1032.

(11) Birk, T.; Schau-Magnussen, M.; Weyhermüller, T.; Bendix, I. Acta Crystallogr. 2011, E67, m1561-m1562.

(12) Rajendiran, T. M.; Kahn, O.; Golhen, S.; Ouahab, L.; Honda, Z.; Katsumata, K. Inorg. Chem. 1998, 37, 5693-5696.

(13) Birk, T.; Bendix, J.; Weihe, H. Acta Crystallogr. 2008, E64, $\mathrm{m} 369-\mathrm{m} 370$.

(14) Meally, S. T.; Mason, K.; McArdle, P.; Brechin, E. K.; Ryder, A. G.; Jones, L. F. Chem. Commun. 2009, 7024-7026.

(15) Tereshchenko, D. S.; Morozov, I. V.; Boltalin, A. I.; Kemnitz, E.; Troyanov, S. I. Zh. Neorg. Khim. 2004, 49, 919-927.

(16) (a) Kaizaki, S.; Takemoto, H. Inorg. Chem. 1990, 29, 49604964. (b) Terasaki, Y.; Kaizaki, S. I. Chem. Soc., Dalton Trans. 1995, 2837-2841. (c) Terasaki, Y.; Fujihara, T.; Schönherr, T.; Kaizaki, $\underline{S}$. Inorg. Chim. Acta 1999, 295, 84-90.

(17) Decurtins, S.; Gross, M.; Schmalle, H. W.; Ferlay, S. Inorg. Chem. 1998, 37, 2443-2449.

(18) Although numerically small, inclusion of both parameters, $J_{\mathrm{Cr}-\mathrm{Gd}}$ and $J_{\mathrm{Gd}-\mathrm{Gd}}$ is statistically warranted since they by the fitting both have relative uncertainties well below $10 \%$ and a mutual correlation coefficient of 0.078 .

(19) (a) Figuerola, A.; Diaz, C.; El Fallah, M. S.; Ribas, J.; Maestro, M.; Mahía, J. Chem. Commun. 2001, 1204-1205. (b) Kou, H.-Z.; Gao, S.; Li, C.-H.; Liao, D.-Z.; Zhou, B.-C.; Wang, R.-J.; Li, Y. Inorg. Chem. 2002, 41, 4756-4762. (c) Akitsu, T.; Einaga, Y. Inorg. Chim. Acta 2006, 359, 1421-1426. (d) Sun, X.-R.; Chen, Z.-D.; Wang, M.-W.; Wang, B.-W.; Yan, F.; Cheung, K.-K. Chin. I. Chem. 2007, 25, 329336.

(20) Sanada, T.; Suzuki, T.; Yoshida, T.; Kaizaki, S. Inorg. Chem. 1998, 37, 4712-4717.

(21) Hodgson, D. J.; Michelsen, K.; Pedersen, E. L. Chem. Soc., Chem. Commun. 1988, 23, 1558-1559.

(22) Pedersen, K. S.; Thuesen, C. Aa.; Schau-Magnussen, M.; Bendix, J., manuscript in preparation.

(23) Evangelisti, M.; Luis, F.; de Jongh, L. J.; Affronte, M. L. Mater. Chem. 2006, 16, 2534-2549.

(24) Sessoli, R. Angew. Chem. Int. Ed. 2012, 51, 43-45.
(25) Richardson, M. F.; Wagner, W. F.; Sands, D. E. I. Inorg. Nucl. Chem. 1968, 30, 1275-1289.

(26) Sheldrick, G. M. Acta Crystallogr. 2008, A64, 112-122.

(27) Macrae, C. F.; Bruno, I. J.; Chisholm, J. A.; Edgington, P. R.; McCabe, P.; Pidcock, E.; Rodriguez-Monge, L.; Taylor, R.; van de Streek, J.; Wood, P. A. L. Appl. Crystallogr. 2008, 41, 466-470.

(28) Tregenna-Piggott, P. L. W.; Sheptyakov, D.; Keller, L.; Klokishner, S. I.; Ostrovsky, S. M.; Palii, A. V.; Reu, O. S.; Bendix, J.; Brock-Nannestad, T.; Pedersen, K.; Weihe, H.; Mutka, H. Inorg. Chem. 2009, 48, 128-137. 